\title{
Local buckling and ultimate strength of slender elliptical hollow sections in compression
}

\author{
F. McCann ${ }^{1}$, C. Fang ${ }^{2}$, L. Gardner ${ }^{3}$, N. Silvestre ${ }^{4}$ \\ ${ }^{1}$ Department of Urban Engineering, School of the Built Environment and Architecture, London South Bank \\ University, London SE1 0AA, UK \\ ${ }^{2}$ Department of Structural Engineering, School of Civil Engineering, Tongji University, Shanghai 200092, \\ China \\ ${ }^{3}$ Department of Civil and Environmental Engineering, Imperial College London, London SW7 2AZ, UK \\ ${ }^{4}$ Department of Mechanical Engineering, IDMEC, LAETA, Instituto Superior Técnico, Universidade de Lisboa, \\ Portugal
}

\begin{abstract}
The local buckling behaviour and ultimate cross-sectional strength of tubular elliptical profiles in compression is examined in this study through numerical modelling. The numerical models were first validated against previous experimental data with good agreement observed, enabling an extensive parametric study to be performed. A total of 270 elliptical sections were simulated in order to examine the influence of cross-section aspect ratio, geometric imperfections and local slendernesses. The obtained ultimate capacities, load-deformation responses and failure modes are discussed. It was found that for lower cross-section aspect ratios the behaviour of the elliptical hollow sections (EHS) was similar to that of cylindrical shells across a number of metrics; however, as the aspect ratio increased, more plate-like stable postbuckling behaviour was observed. Imperfection sensitivity was found to decrease with increasing slenderness and aspect ratio. The influence of the shape of the initial imperfection on the strengths of the EHS columns was also assessed and was found to be generally limited. Finally, a design method has been proposed for Class 4 EHS members that reflects the reduction in capacity due to local buckling with increasing slenderness, but also recognises the improved postbuckling stability with increasing aspect ratio; the proposals were shown to provide safe and accurate predictions for the strengths of the EHS columns with nondimensional local slendernesses up to 2.5 and aspect ratios from
\end{abstract}


1.1 to 5.0 .

Keywords: Class 4 sections; elliptical hollow sections; local buckling; numerical modelling; postbuckling; steel structural design. 


\section{Introduction}

In recent years, structural steel elliptical hollow section (EHS) members have attracted increased research focus. This can be attributed to their introduction and availability as hot-finished products [1], their aesthetic properties, which have led to their use in high-profile projects such as Heathrow Terminal 5, and their enhanced flexural properties about the major principal axis compared to CHS tubes [2]. Research into the structural response of EHS tubes has included testing, numerical modelling and the development of design rules for cross-sections in compression and bending [3-5], analysis of the buckling response of EHS columns [6], stainless steel EHS columns [7], EHS columns in fire [8], concrete-filled columns [9-12], beams [13] and beam-columns [14], and the behaviour of members in shear [15].

The focus of the present investigation is on the behaviour and strength of slender EHS tubes under compression. Potential applications of such members include aesthetic lightweight cladding rails, mullion posts and concrete-filled steel tubes in composite construction. A number of the current range of hot-finished elliptical hollow sections [16], which have been used in a range of structural applications, as outlined in [17], are Class 4 in compression. Cold-formed elliptical sections are also produced from both structural carbon steel [18] and stainless steel $[7,19]$, and are often of slender proportions. Although cold-formed profiles are not specifically addressed in the present study, it is envisaged that the findings and proposed design approach also apply to these sections since the level of local geometric imperfections in cold-formed and hot-finished tubular sections are generally similar [20] and the dominant through-thickness residual stresses in cold-formed tubular sections have been shown to not have a strong influence on their local stability [21]. The above assertions should however be verified in future research, and if necessary, lower strength curves can be assigned to 
cold-formed sections through the use of a higher imperfection factor (see Section 4).

Early studies of elastic local buckling and postbuckling of elliptical hollow sections were reported by [22-24], while more recent work has been reported by $[2,25,26]$. A key finding of these investigations is that, in contrast to CHS tubes, EHS tubes in compression can have stable postbuckling responses and may therefore be able to resist further load beyond the elastic buckling load. Previous numerical studies [25] into the elastic local postbuckling behaviour of EHS columns led to the following conclusions: i) the maximum stress that a fully-elastic EHS tube with a moderate to high aspect ratio $(a / b \geq 2.0)$ could carry is higher than its critical buckling stress $f_{\text {cr }}$ due to the stable postbuckling response, where $2 a$ and $2 b$ are the larger and smaller outer diameters of the EHS, respectively, as shown in Figure 1. The slope of the ascending post-peak equilibrium path increased with increasing aspect ratio $a / b$ and could reach up to $40 \%$ of the initial slope of the linear primary path; ii) concentrated zones of compressive stress in an EHS column were located near the point of minimum radius of curvature (akin to the edges of simply-supported plates), while the zones of maximum radius of curvature experienced an approximately uniform and relatively low compressive stress level; iii) the imperfection sensitivity significantly decreased with increasing aspect ratio $a / b$, representing a transition from shell-type behaviour (imperfection sensitive) for EHS columns with low $a / b$ ratios to plate-type behaviour (imperfection insensitive) with increasing $a / b$ ratios. These observations suggest that strength curves for elliptical sections may need to be both a function of local slenderness to allow for the increased susceptibility to local buckling and cross-sectional aspect ratio $a / b$ to reflect the differing postbuckling stability. The present study explores the buckling, postbuckling and collapse responses of slender elliptical cross-sections in compression with elastic-plastic material behaviour. 
Firstly, the development and validation of a numerical model to simulate the response of EHS in compression is described. After achieving satisfactory agreement between the numerical results generated herein and previous experimental results, the axial compressive response of EHS stub columns with aspect ratios ranging from 1.1 to 5.0 is examined. Other parameters varied in the study include local buckling slenderness, imperfection amplitude and imperfection shape. The results of the parametric study are used as a basis for the formulation of new strength and effective area reduction curves for the design of Class 4 EHS compression members. Comparisons are made with existing provisions from Eurocode 3 for the design of CHS tubes. Thus, the objectives of the present study can be summarised: i) to establish a database of resistances of slender elliptical cross-sections in compression; ii) to assess the influences of various design parameters on these resistances; iii) to assess the suitability of current design provisions for Class 4 CHS for the design of EHS; iv) propose new design rules for the design of Class 4 EHS in compression.

\section{Development and validation of numerical model}

In this section, the modelling strategy used to simulate the EHS stub columns in compression is described, followed by the validation of the model against previous experiments.

\subsection{Description of finite element model}

\subsubsection{Geometry}

A numerical model was developed using the finite element analysis software ABAQUS [27]. Five different aspect ratios were considered, namely, $a / b=1.1,1.5,2.0,3.0$ and 5.0. The reference geometry is based on the commercially-available $300 \times 150$ series of elliptical sections with $a / b=2.0$. The cross-sectional geometry for the other four aspect ratios was 
based on maintaining a constant perimeter $P$ of $726.3 \mathrm{~mm}$. It was found previously that length effects are reduced in EHS with higher aspect ratios [2]; a length effect coefficient proposed by [2] was used in the present study to define suitable lengths for the EHS models so that length effects were minimised, while also ensuring that global buckling was precluded.

\subsubsection{Meshing}

The EHS tubes were meshed using 4-node isoparametric reduced-integration S4R shell elements with a characteristic (approximately square) element size of $9 \mathrm{~mm}$, resulting in the EHS stub columns being discretised into 80 elements around the perimeter. This mesh density was found previously to capture the local behaviour of EHS shells adequately [25].

\subsubsection{Boundary conditions}

Rigid plates were attached to the end sections of the stub columns using tie constraints. These rigid end plates were modelled by means of 3-node R3D3 finite elements. Fully-fixed boundary conditions were imposed on one end plate, while a compressive axial load was applied at the centroid of the other rigid end plate, on which all degrees-of-freedom except longitudinal displacement were fixed.

\subsubsection{Analysis procedure}

Each simulation was conducted in two steps. The first step was a linear eigenvalue analysis from which the elastic buckling stress for each buckling mode was obtained, with the critical buckling stress $f_{c r}$ being that associated with the first valid buckling mode (see Section 2.1.6). The mode shape provided the form of the initial imperfection for the second step, a Riks arclength continuation analysis, which simulated the nonlinear behaviour of the EHS up to 
and beyond the ultimate load. The sensitivity of the system to initial imperfections was assessed by running simulations with three different imperfection amplitudes for each combination of cross-section and yield stress.

\subsubsection{Material modelling}

For the linear eigenvalue analyses, the stub column material was assumed to be homogeneous, isotropic and linearly-elastic with a Young's modulus of $216400 \mathrm{MPa}$ in keeping with the experimental observations of [4] and a Poisson's ratio of 0.3. For the Riks analyses, elastic-perfectly plastic material models were adopted, with three different yield stresses considered for each aspect ratio. No residual stresses were included in the numerical analyses since they have been found to be of very low magnitude in hot-finished elliptical tubes $[4,5]$. While residual stresses in cold-formed steel might be significant if the folding radius is small, which is the case of open cold-formed sections, this is not the case in commercial EHS tubes [28]. If residual stresses were to be modelled, this could be achieved by imposing a through-thickness temperature variation, so that the inner surface of the tube is in circumferential compression while the outer surface of the tube is in tension.

\subsubsection{Geometric imperfections}

Owing to the limited data available on geometric imperfections in EHS tubes, the mode shapes considered in this paper are based on previous guidance [25] whereby the mode shape was assumed to be symmetric about the principal axes with an odd number of longitudinal half-waves along the column length and with the point of maximum local radius of curvature (where buckling initiates) at mid-span assumed to move inward. Considering the elastic buckling mode shapes shown in Figure 2, it can be observed that for the same tube thickness, EHS tubes with higher aspect ratios tend to have fewer half-waves along the member length. 
Also, thinner sections tend to have more half-waves, which can lead to unrealistic imperfection shapes being predicted for sections with low aspect ratios and very thin walls [25]. Appropriate wall thickness values $t_{\text {imp }}$ were selected for different sections in order to obtain realistic mode shapes to be used as initial imperfections; the values of $t_{\text {imp }}$ are given in Table 1. In the interests of consistency, the same mode shapes were applied to sections with the same aspect ratio and length. A further justification for using a consistent imperfection shape for the same aspect ratio is that EHS members of the same aspect ratio but various thicknesseses are formed using the same fabrication process, which would be expected to lead to similar initial imperfection shapes. The influence of including alternative initial imperfection shapes is discussed in Section 3.5. The imperfection amplitudes $\Delta w$ were calculated using an expression modified from clause D.1.2.2(1-2) of EN 1993-1-6 [29] for circular shells for use with elliptical shells. The modified form of the expression is:

$$
\Delta w=\frac{t}{Q} \sqrt{\frac{r_{\mathrm{eq}}}{t}}
$$

where $r_{\mathrm{eq}}=\left(a^{2} / b\right)$ and $t$ are the equivalent radius and thickness of the elliptical shell, respectively, and $Q$ is a fabrication quality parameter. In the present study, three different levels of initial imperfection amplitude were considered, namely, $\Delta w=0.1 t, Q=40$ (Class A - excellent quality), and $Q=25$ (Class B - high quality). Upon comparison of previous measurements [4] of geometric imperfections of hot-finished EHS tubes with these different levels of imperfection, it was found that the Class A imperfections provided an upper bound to the measured values and can be assumed to represent a level of imperfection amplitude suitable for the design of hot-finished EHS. 


\subsection{Validation of numerical model}

Results from an experimental investigation [4] into the behaviour and strength of hot-finished EHS stub columns were used to validate the numerical model. The three most slender cross-sections tested by [4] were selected for comparison: $150 \times 75 \times 4$ EHS, $400 \times 200 \times 8$ EHS and $500 \times 250 \times 8$ EHS. The ultimate-to-yield stress $\left(f_{\mathrm{u}} / f_{\mathrm{y}}\right)$ ratios for the selected specimens ranged between 0.95 and 0.99 , suggesting that they were Class 4 cross-sections.

The cross-sectional dimensions, lengths, steel properties and maximum imperfection amplitudes measured by [4] were used in the validation study. Two specimens of each cross-section were tested, but since the difference between the geometry of the respective specimens was small (the maximum differences of geometric dimensions and material properties were $1.0 \%$ and $3.0 \%$, respectively), average properties were used for each section in the numerical model. The typical predicted failure mode for the $150 \times 75 \times 4$ EHS stub columns is compared with the corresponding deformed test specimen in Figure 3, while the numerical and experimental load-end shortening responses of the EHS columns are compared in Figure 4. In general, good agreement between the experimental and numerical results was observed when considering the deformation mode, initial stiffness, ultimate load $\left(P_{u}\right)$, and general load-end shortening response. It can be seen that the load-end shortening responses remain linear up to the ultimate load. A comparison of the test results and the FE predictions for the ultimate load is given in Table 2, with a maximum error of $3.9 \%$. A slight discrepancy is found in the post-peak descending load path, but the overall trend is still well captured. In general, the simulation of the test results is found to be satisfactory, enabling an extensive parametric study to be conducted. 


\section{Numerical parametric study}

Having shown that good agreement exists between the predictions of the FE model and the experimental results of [4], a parametric study was conducted that examined the influences of a number of key variables. In this section, the parameters varied in the study and the subsequent results obtained are presented and discussed.

\subsection{Parameters for numerical studies}

A range of nondimensionalised local buckling slendernesses $\bar{\lambda}_{\ell}$, as defined by Eq.(2), was considered by varying the thickness $t$ and yield strength $f_{y}$ of the EHS across the five examined aspect ratios.

$$
\bar{\lambda}_{\ell}=\sqrt{\frac{f_{\mathrm{y}}}{f_{\mathrm{cr}}}}
$$

where $f_{c r}$ is the elastic critical local buckling stress, which was determined from:

$$
f_{\text {cr }}=\frac{E}{\sqrt{3\left(1-v^{2}\right)}} \frac{2 t}{D_{\text {eq }}}
$$

where $D_{\text {eq }}=2 r_{\text {eq }}=2\left(a^{2} / b\right)$ is the equivalent diameter of the EHS under pure compression. Since the focus of this study is on the behaviour and strength of slender cross-sections, the selected EHS geometries were mainly Class 4. An elliptical hollow section can be classified as Class 4 if it satisfies the following condition, which was formulated by [3] for EHS columns based on the EN 1993-1-1 [30] classification limits for CHS columns:

$$
\frac{D_{\text {eq }}}{t \varepsilon^{2}}=\frac{2\left(a^{2} / b\right) f_{y}}{235 t}>90
$$

which for, $E=216400 \mathrm{MPa}$ [4], corresponds to a local slenderness requirement for a Class 4 EHS of $\bar{\lambda}_{\ell}>0.284$, while for $E=210000 \mathrm{MPa}$ [30], the corresponding limiting slenderness is 0.288 . The thickness $t$, yield strength $f_{\mathrm{y}}$, critical buckling stress $f_{\text {cr }}$ from linear eigenvalue 
analysis, slenderness $\bar{\lambda}_{\ell}$ and imperfection amplitude $\Delta w$ for the 270 cases (five aspect ratios $\times$ six thicknesses $\times$ three yield strengths $\times$ three imperfection classes) simulated in the parametric study are given in Table 3 . In order to cover a large range of local slendernesses up to a maximum of $\bar{\lambda}_{\ell}=2.5$, in some cases the considered yield strength $f_{y}$ and wall thicknesses were beyond the practical range.

\subsection{Failure modes}

A summary of the various failure modes encountered in the parametric study is shown in Figure 5. There was good agreement observed between the failure modes determined from the numerical analysis and those observed in the test specimens in [4]. There was also good correlation with the predicted failure modes in [31], where four deformation modes were identified: i) the shell-like "elephant foot" (EF) mechanism which is more prevalent for small imperfection amplitudes, with outward bulges forming a concertina; ii) the shell-like Yoshimura (Y) mechanism, with sequential folding at mid-height, which occurs for imperfection modes with inward displacements at mid-height; iii) the plate-like flip disc (FD) and iv) split flip disc (SFD) mechanisms, which are inward-facing with two parabolic hinge lines folding inwards and outwards, respectively [32]. These latter two mechanisms are most likely to occur in EHS with imperfection amplitudes typically found in practice. For sections with an aspect ratio of 1.1, the failure modes tended to be either the EF mechanism for stockier sections or a superposition of the EF and FD mechanisms as the slenderness increased, i.e, with increasing yield stress or thinner tube walls. For $a / b=1.5$ and a low yield strength, a combined FD and EF mechanism occurred with the FD mechanism being more prominent at mid-height while the EF mechanism appeared at the section ends. For higher yield strengths, the $\mathrm{Y}$ mechanism was observed with sequential folding and crushing of the stiff corners occurring at mid-height. This observation is coherent with the findings of [31] 
since the imperfection shape was symmetrical with a relatively large inward displacement at mid-height. For $a / b=2.0$ and a low yield strength, the FD mechanism was found to occur at mid-height, while for a high yield strength a Y mechanism generally occurred, as for sections with $a / b=1.5$. For sections with high aspect ratios equal to 3.0 and 5.0, plate-like collapse mechanisms (FD or SFD) are expected; however, the observed mechanisms generally featured a superposition of the Y and the FD mechanisms: the inward FD deformation occurs along with the sequential folding and crushing of the stiff corners typical of the Y mechanism. It should be noted that for $a / b=5.0$, the plate-like FD mechanism becomes more dominant, with only one fold forming at mid-height.

\subsection{Load-displacement behaviour}

The load-end shortening curves obtained from the FE models are presented in normalised form $\left(f / f_{\mathrm{cr}}\right.$ vs. $e / e_{\mathrm{cr}}$, where $e$ is the end shortening and $e_{\mathrm{cr}}$ is the end shortening at the elastic buckling stress $f_{\text {cr }}$ obtained from a linear eigenvalue analysis) in Figures 6 to 10 for each of the five considered cross-section aspect ratios. For each aspect ratio, curves are given for three thicknesses $(t=8.7 \mathrm{~mm}, 2.1 \mathrm{~mm}$ and $1.0 \mathrm{~mm})$ in order to present results for a range of slendernesses. It can be seen how the postbuckling behaviour is influenced by the aspect ratio and also by the slenderness of the cross-sections. In the following discussion, $f_{\mathrm{u}}$ is the maximum average stress resisted by the cross-section, while $f_{\mathrm{b}}$ is the average stress at the point at which buckling initiates. In specimens exhibiting a stable postbuckling response, $f_{\mathrm{u}}>$ $f_{\mathrm{b}}$ (and in some cases, $f_{\mathrm{u}}>f_{\mathrm{cr}}$ ). In specimens exhibiting a weak or unstable postbuckling response where load carrying capacity is diminished after the initiation of buckling, $f_{\mathrm{u}}<f_{\mathrm{b}}$. For the lowest aspect ratio of 1.1, the behaviour resembles that of cylindrical shells, in that there exists an unstable postbuckling response where load carrying capacity is compromised for all but the highest slendernesses. For the stockier sections, less imperfection sensitivity is 
observed, but as the slenderness increases, imperfection sensitivity is increased. For $a / b=1.5$, the postbuckling response is more dependent on the slenderness. For stockier sections, i.e., with greater wall thickness or lower yield strength, the response tends to be unstable; however, as the slenderness increases, there is a tendency for the response to regain stability after some unloading, with an ultimate load greater than the buckling load for the most slender cases. Imperfection sensitivity is more readily apparent in the stocky sections. For $a / b$ $=2.0$, for the lowest slendernesses, the response is still unstable, but as the slenderness increases the stable postbuckling response is stronger than for the lower aspect ratios. Imperfection sensitivity is least for the stockier sections and increases with slenderness, particularly as the tube wall thickness decreases. For $a / b=3.0$, as slenderness increases, so too does the relative strength of the postbuckling response, with the ultimate load often exceeding the elastic critical buckling load for the higher slendernesses. Since the strength of the postbuckling response increases with slenderness, the sensitivity of the response to imperfections considerably decreases. For $a / b=5.0$, there is a strong postbuckling response even in specimens with low slenderness, with $f_{\mathrm{u}}$ greater than $f_{\mathrm{b}}$ except in the most stocky sections, which is to be expected since the yield strength was not sufficient to maintain a stable postbuckling response and unloading was observed. Overall however, the trend of reduced imperfection sensitivity with increasing slenderness can be observed. In summary, the overall trends that can be observed from the load-displacement graphs are: i) increasing stability of the postbuckling response, and thus greater normalised load-carrying capacity, with increasing aspect ratio; ii) increasing stability of the postbuckling response with increasing local slenderness; iii) decreasing imperfection sensitivity with increasing slenderness. 


\subsection{Strength reduction}

The reduction in strength of the EHS stub columns is characterised by the ultimate-to-yield stress ratio $\rho=f_{\mathrm{u}} / f_{\mathrm{y}}$, or in terms of loads, $\rho=P_{\mathrm{u}} / P_{\mathrm{y}}$, where $P_{\mathrm{u}}$ is the maximum load obtained by the stub columns and $P_{\mathrm{y}}$ is the yield load. It has been shown previously [25] that fully-elastic EHS with higher aspect ratios in compression exhibit more plate-like postbuckling behaviour, while it can be seen from the discussion in Section 3.3 that EHS with lower aspect ratios display behaviour more similar to cylindrical shells. Owing to the redistribution of compressive stresses in the postbuckling range from the areas of lower local curvature where local buckling is the most severe towards the areas of the elliptical sections with higher local curvature, the concept of a 'loss of effectiveness' can be adopted as the basic design approach. Thus, the effective area $A_{\text {eff }}$ of the elliptical section can be obtained from:

$$
\rho=\frac{f_{\mathrm{u}}}{f_{\mathrm{y}}}=\frac{A_{\mathrm{eff}}}{A} .
$$

When considering perfect elastic buckling, the buckling curve is given by:

$$
\rho=\frac{1}{\bar{\lambda}_{\ell}^{2}} \leq 1
$$

The current provisions of EN 1993-1-6 [29] for the local buckling reduction factor of Class 4 CHS columns are:

$$
\rho=\left\{\begin{array}{ccc}
1 & \text { for } & \bar{\lambda}_{\ell} \leq 0.2 \\
1-0.6 \frac{\bar{\lambda}_{\ell}-0.2}{\bar{\lambda}_{\mathrm{p}}-0.2} & \text { for } & 0.2<\bar{\lambda}_{\ell}<\bar{\lambda}_{\mathrm{p}} \\
\frac{\alpha}{\bar{\lambda}_{\ell}^{2}} & \text { for } & \bar{\lambda}_{\ell} \geq \bar{\lambda}_{\mathrm{p}}
\end{array}\right.
$$

where the nondimensionalised plastic limit slenderness $\bar{\lambda}_{\mathrm{p}}$ and the imperfection factor $\alpha$ are given by: 


$$
\begin{gathered}
\bar{\lambda}_{\mathrm{p}}=\sqrt{\frac{\alpha}{0.4}} \\
\alpha=\frac{0.62}{1+1.91\left(\frac{\Delta w}{t}\right)^{1.44}}
\end{gathered}
$$

The Winter curve for plate buckling, adopted in EN 1993-1-5 [33], is given by:

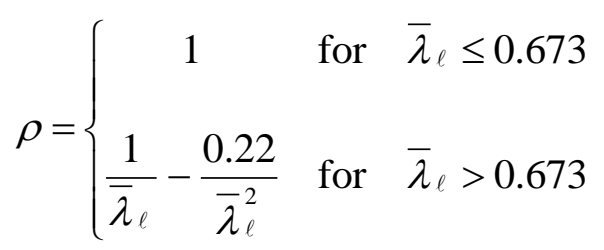

Given that expressions for the design of Class 4 EHS do not exist at present, one possible approach to extending the provisions of EN 1993-1-6 [29] to EHS members is to apply the equivalent diameter concept to Eq.(7); however, this approach neglects the stable postbuckling response and reduced imperfection sensitivity exhibited by sections with higher aspect ratios. In Section 4, the results of the parametric study are used as a basis to formulate design rules that take these factors into account more comprehensively.

In Figures 11 to 15 , comparisons are made between the strength reduction $\left(f_{\mathrm{u}} / f_{\mathrm{y}}\right)$ results from the parametric study (shown by solid markers) for the various aspect ratios and the CHS curves using the EHS equivalent diameters (shown by hollow markers), the Winter curve (shown by solid lines), the elastic buckling curve (shown by dashed lines) and the proposed design curves outlined in Section 4. From the plots of strength reduction factor against slenderness, it can be observed that as the slenderness increases, the strength of the sections with higher aspect ratios is maintained more effectively than those with lower aspect ratios, particularly for specimens with the larger, Class B, imperfections. This is an indication that the behaviour of the elliptical sections with higher aspect ratios is tending towards more plate-like behaviour, as represented by the Winter curve. Additionally, it can be seen upon 
examination of the spread of results between the three imperfection classes that imperfection sensitivity is considerably lower in the sections with the higher aspect ratios, despite the Class A and Class B imperfections being rather high for some sections. These two observations are commensurate with the findings of [31]. It is also confirmed from examination of the graphs that the CHS curves using the equivalent EHS diameters are overly conservative and wrongly predict significant imperfection sensitivity for sections with high aspect ratios. This is not a shortcoming of the existing curves, but simply a reflection of the fact that they are intended for CHS and therefore do not capture the increasing postbuckling stability of EHS with increasing aspect ratios. The local buckling reduction factors for the EHS with high aspect ratios, $a / b=5$, are higher than those with low aspect ratios but still fall short of the Winter curve. It is likely that, for closer convergence to be achieved, the aspect ratio of the EHS member would have to become unrealistically high, such that the geometry of the ellipse along the major axis would more closely approximate the zero-curvature of a flat plate. Nonetheless, the improving postbuckling stability with increasing $a / b$ ratios is clear, and should be reflected in the design approach - see Section 4.

\subsection{Influence of initial imperfection shape}

In order to assess the influence of different initial imperfection mode shapes on the ultimate loads of the EHS stub columns, a comparison was conducted between the results of the main parametric study and similar numerical simulations conducted using alternative initial imperfection mode shapes. Firstly, the alternative imperfection shapes were such that the initial deformation was outwards at the mid-length of the specimens. Also, the wall thickness used in the linear eigenvalue analysis to determine the alternative mode shapes was fixed at 8 $\mathrm{mm}$; this led to fewer longitudinal half-waves being present than would be the case if thinner sections were used. The alternative mode shapes were included in the nonlinear analyses with 
an imperfection amplitude of $0.1 t$. The results of the comparison are summarised in Figure 16. It can be seen that in the majority of cases the ratio between the ultimate stresses from the main parametric study $f_{\mathrm{u}, 1}$ and those from applying the alternative imperfection shapes $f_{\mathrm{u}, 2}$ is quite close to unity, suggesting that, in general, the form of the imperfection mode shape does not have a substantial influence on the ultimate strength. A more significant result of the comparison is that $f_{\mathrm{u}, 1} / f_{\mathrm{u}, 2}<1$ for the vast majority of cases, with a minimum value of 0.8 , which suggests that selecting imperfection shapes with inward deformations at the mid-length, as used in the main parametric study, leads to more conservative predictions for ultimate strength.

\section{Proposed design method}

In this section, the results of the main parametric study are used to define design strength reduction curves for Class 4 EHS in compression. The strength reduction curves were calibrated for each of the aspect ratios examined in the study, using the existing CHS design rules from EN 1993-1-6 [29] as a basis, and are given in Eqs.(11) to (19).

$$
\rho=\left\{\begin{array}{ccc}
1 & \text { for } & \bar{\lambda}_{\ell} \leq \bar{\lambda}_{0} \\
\rho_{1} & \text { for } & \bar{\lambda}_{0}<\bar{\lambda}_{\ell}<\lambda_{\mathrm{p}} \\
\rho_{2} & \text { for } & \bar{\lambda}_{\ell} \geq \bar{\lambda}_{\mathrm{p}}
\end{array}\right.
$$

where:

$$
\begin{gathered}
\bar{\lambda}_{0}=0.288 \\
\alpha^{\prime}=\frac{0.62}{1+1.91\left(\frac{\Delta w}{(a / b) t}\right)^{1.44}} \\
\bar{\lambda}_{\mathrm{p}}=\sqrt{\frac{\alpha^{\prime}}{0.4}}+\left(\bar{\lambda}_{0}-\sqrt{\frac{\alpha^{\prime}}{0.4}}\right)\left(1-\frac{1}{(a / b)^{0.1}}\right)
\end{gathered}
$$




$$
\begin{gathered}
\mu=1-\frac{\beta_{1}}{\bar{\lambda}_{\mathrm{p}}}-\frac{\beta_{2}}{\bar{\lambda}_{\mathrm{p}}{ }^{2}} \\
\beta_{1}=1-\frac{1}{(a / b)^{0.5}} \\
\beta_{2}=\frac{0.09+\alpha^{\prime}}{(a / b)}-0.09 \\
\rho_{1}=1-\mu \frac{\bar{\lambda}_{\ell}-\bar{\lambda}_{0}}{\bar{\lambda}_{\mathrm{p}}-\bar{\lambda}_{0}} \\
\rho_{2}=\frac{\beta_{1}}{\bar{\lambda}_{\ell}}+\frac{\beta_{2}}{\bar{\lambda}_{\ell}^{2}}
\end{gathered}
$$

The key features of the proposed design curves are: i) as was shown in Section 3.1, a cross-sectional slenderness limit of 90 (with $E=210000 \mathrm{MPa}$ as specified in EN 1993-1-1 [30]) corresponds to a limiting local buckling slenderness of $\bar{\lambda}_{\ell}=0.288$, therefore for local buckling slendernesses less than 0.288 , the sections can be assumed to be fully effective and $\rho=1$; ii) similarly to the CHS design curves, the proposed formulae contain a linear portion $\rho_{1}$ and a curved portion $\rho_{2}$. Reflecting the results of the parametric study, the range of the linear portion diminishes with increasing aspect ratio; iii) the modified imperfection factor $\alpha$, takes into account the reduced imperfection sensitivity of sections with higher aspect ratios. The results of the parametric study are compared to the design proposal in Figures 11 to 15 for the five different cross-section aspect ratios examined, while a summary of the design curves for the five different aspect ratios investigated in the present study is shown in Figure 17, where Class A levels of imperfection amplitudes have been applied.

In Figures 18 to 22 , the ratios of ultimate stress as determined from the numerical model $f_{\mathrm{u}, \mathrm{FE}}$ to the design ultimate stress $f_{\mathrm{u}, \mathrm{D}}$ are presented for both the proposed EHS design method and the equivalent diameter CHS method with Class A imperfections assumed, with values 
greater than unity indicating safe-sided predictions. It can be seen that the proposed EHS design method, provides safe and accurate predictions for all cases bar one, with values of $f_{\mathrm{u}, \mathrm{FE}} / f_{\mathrm{u}, \mathrm{D}}<1.8$. The direct use of EN 1993-1-6 [29] with an equivalent CHS diameter leads to increasingly conservative predictions with increasing aspect ratio and slenderness, with a maximum value of $f_{\mathrm{u}, \mathrm{FE}} / f_{\mathrm{u}, \mathrm{D}}$ of 5.6. Design examples are provided in the Appendix to illustrate the proposed design method.

\section{Conclusions}

The local buckling and ultimate strength of Class 4 elliptical hollow sections (EHS) in compression have been investigated using numerical methods. Numerical models were first validated against previous experimental results, after which an extensive parametric study was conducted. The parametric study included elliptical sections with aspect ratios from 1.1 to 5.0, nondimensionalised local buckling slendernesses from 0.21 to 2.49 and wall thicknesses from $0.7 \mathrm{~mm}$ to $8.7 \mathrm{~mm}$. Three different imperfection classes were also considered: $\Delta w=0.1 t$, Class A imperfections and Class B imperfections. Comparison with previous measurements [4] of imperfections of EHSs has shown that assuming a Class A level of imperfection provided an upper bound for imperfection amplitudes that was suitable for the design of hot-finished EHS.

It was found, upon examination of the numerical results that EHS with low aspect ratios displayed behaviour more akin to cylindrical shells, in that an unstable postbuckling response was observed along with noticeable imperfection sensitivity, while sections with higher aspect ratios exhibited more plate-like behaviour, with ultimate strengths often exceeding the elastic buckling stress. A general corresponding transition in failure mechanisms was also observed, changing from elephant foot and Yoshimura modes for low 
aspect ratios to flip-disc and split flip-disc modes for high aspect ratios.

Finally, a design method has been proposed for Class 4 EHS members that reflects the reduction in capacity due to local buckling with increasing slenderness, but also recognises the improved postbuckling stability with increasing aspect ratio; the proposals were shown to provide safe and accurate predictions for the strengths of the EHS columns with nondimensional local slendernesses up to 2.5 and aspect ratios from 1.1 to 5.0. Comparisons were also made with the approach of using an equivalent diameter with the Class $4 \mathrm{CHS}$ design curves from EN 1993-1-6 [29], but failure to capture the improving postbuckling stability with increasing aspect ratio led to overly conservative results.

\section{Acknowledgments}

The authors gratefully acknowledge the financial support given by FCT, through IDMEC, under LAETA, project UID/EMS/50022/2013. The authors also wish to recognise the considerable assistance of Mr. Hammad El-Jisr of Imperial College London in the numerical study.

\section{References}

[1] Comité Européen de Normalisation. EN 10210-1:2006 Hot finished structural hollow sections of non-alloy and fine grain steels - Part 1: Technical delivery conditions. British Standards Institution, 2006.

[2] Ruiz-Teran AM, Gardner L. Elastic buckling of elliptical tubes. Thin-Walled Structures 2008;46(11):1304-1318.

[3] Gardner L, Chan TM. Cross-section classification of elliptical hollow sections. Steel and Composite Structures 2007;7(3):185-200.

[4] Chan TM, Gardner L. Compressive resistance of hot-rolled elliptical hollow sections. 
Engineering Structures 2008;30(2):522-532.

[5] Chan, TM, Gardner L. Bending strength of hot-rolled elliptical hollow sections, Journal of. Constructional Steel Research 2008;64(9):971-986.

[6] Chan TM, Gardner L. Flexural buckling of elliptical hollow section columns, Journal of Structural Engineering ASCE 2009;135(5):546-557.

[7] Theofanous M, Chan TM, Gardner L. Structural response of stainless steel oval hollow section compression members, Engineering Structures 2009;31(4):922-34.

[8] Scullion T, Ali F, Nadjai A. Experimental study on performance of elliptical section steel columns, under hydrocarbon fire, Journal of Constructional Steel Research 2011;67:986-991. [9] McCann F, Gardner L, Qiu W. Experimental study of slender concrete-filled elliptical hollow section beam-columns, Journal of Constructional Steel Research 2015;113:185-194.

[10] Espinos, A., Romero, M. L., Portolés, J, M., Hospitaler, A. 2014. Ambient and fire behavior of eccentrically loaded elliptical slender concrete-filled tubular columns. Journal of Constructional Steel Research, 100, 97-107.

[11] Ren, Q.-X., Han, L.-H., Lam, D., Li, W. 2014. Tests on elliptical concrete filled steel tubular (CFST) beams and columns. Journal of Constructional Steel Research, 99, 149-160.

[12] Sheehan, T, Dai, X. H., Chan, T. M., Lam, D. 2012. Structural response of concrete-filled elliptical steel hollow sections under eccentric compression. Engineering Structures, 45, 314-323.

[13] Silvestre N. Buckling behaviour of elliptical cylindrical shells and tubes under compression, International Journal of Solids and Structures 2008;45(16):4427-4447.

[14] Law KH, Gardner L. Buckling of elliptical hollow section members under combined compression and uniaxial bending, Journal of Constructional Steel Research 2013;86:1-16.

[15] Gardner L, Chan TM, Wadee MA. Shear response of elliptical hollow sections, Proceedings of the Institution of Civil Engineers - Structures and Buildings 2008;161(6):301-309.

[16] Steel Construction Institute. Steel building design: Design data. Publication Number P363. Steel Construction Institute 2013.

[17] Chan TM, Gardner L, Law KH. Structural design of elliptical hollow sections: a review. Proceedings of the Institution of Civil Engineers - Structures and Buildings 2010;163(6):391-402.

[18] Zhu JH, Young B. Design of cold-formed steel oval hollow section columns, Journal of Constructional Steel Research 2012;71:26-37.

[19] Theofanous M, Chan TM, Gardner L. Flexural behaviour of stainless steel oval hollow 
sections. Thin-Walled Structures 2009;47(6-7):776-787.

[20] Gardner L, Saari N, Wang F. Comparative experimental study of hot-rolled and cold-formed rectangular hollow sections, Thin-Walled Structures 2010;48(7):495-507.

[21] Jandera M, Gardner L, Machacek J. Residual stresses in cold-rolled stainless steel hollow sections, Journal of Constructional Steel Research, 2008;64(11):1255-1263.

[22] Kempner J, Chen YN. Large deflections of an axially compressed oval cylindrical shell, Proceedings of the 11th International Congress of Applied Mechanics, Munich, 1964.

[23] Tennyson RC, Booton M, Caswell RD. Buckling of imperfect elliptical cylindrical shells under axial compression, AIAA Journal 1971;9(2):250-5.

[24] Feinstein G, Erickson B, Kempner J. Stability of oval cylindrical shells. Experimental Mechanics, 1971;11(11):514-20.

[25] Silvestre N, Gardner L. Elastic local postbuckling of elliptical tubes, Journal of Constructional Steel Research 2011;67(3):281-292.

[26] Abela JM, Gardner L. Elastic buckling of elliptical tubes subjected to generalised linearly varying stress distributions, Thin-Walled Structures 2012;58:40-50.

[27] ABAQUS. ABAQUS Analysis User's manual, v6.12.3, USA: Dassault Systems Simulia Corp., Providence; 2012.

[28] Moen CD, Igusa T, Schafer BW. Prediction of residual stresses and strains in cold-formed steel members, Thin-Walled Structures 2008;46(11):1274-1289.

[29] Comité Européen de Normalisation. EN 1993-1-6:2007 Eurocode 3 - Design of steel structures, Part 1.6: General rules - Strength and stability of shell structures, CEN, 2007.

[30] Comité Européen de Normalisation. EN 1993-1-1:2005 Eurocode 3 - Design of steel structures, Part 1.1: General rules and rules for buildings, CEN, 2005.

[31] Insausti A, Gardner L. Analytical modelling of plastic collapse in compressed elliptical hollow sections. Journal of Constructional Steel Research 2011;67:678-89.

[32] Murray N. Introduction to the theory of thin-walled structures, Oxford: Oxford University Press, 1984.

[33] Comité Européen de Normalisation. EN 1993-1-5:2006 Eurocode 3 - Design of steel structures, Part 1.5: Plated structural elements, CEN, 2006. 


\section{Appendix: Worked design examples}

Example 1

In the first example, it is required to determine the resistance of a $300 \times 150 \times 4$ EHS member in compression. The properties of the member are: $a=150 \mathrm{~mm}, b=75 \mathrm{~mm}, a / b=$ $2.0, t=4 \mathrm{~mm}$, the equivalent diameter $D_{\mathrm{eq}}=2 a^{2} / b=600 \mathrm{~mm}\left(r_{\mathrm{eq}}=300 \mathrm{~mm}\right)$ and $A=2857$ $\mathrm{mm}^{2}$. The yield strength $f_{y}=450 \mathrm{MPa}$, and the modulus of elasticity $E=210000 \mathrm{MPa}$.

The slenderness of the section is given by:

$\frac{D_{\text {eq }}}{t \varepsilon^{2}}=\frac{D_{\text {eq }} f_{y}}{235 t}=\frac{600 \times 450}{235 \times 4.0}=287>90$,

and thus the section is Class 4. The imperfection is assumed to be Class A, therefore:

$$
\Delta w=\frac{t}{Q} \sqrt{\frac{r_{\mathrm{eq}}}{t}}=\frac{4}{40} \sqrt{\frac{300}{4}}=0.866 \mathrm{~mm}
$$

The imperfection factor $\alpha$ is thus:

$$
\alpha^{\prime}=\frac{0.62}{1+1.91\left(\frac{\Delta w}{(a / b) t}\right)^{1.44}}=\frac{0.62}{1+1.91\left(\frac{0.866}{2 \times 4}\right)^{1.44}}=0.575
$$

The local buckling limit slenderness is $\bar{\lambda}_{0}=0.288$, while the plastic limit slenderness is:

$$
\bar{\lambda}_{\mathrm{p}}=\sqrt{\frac{\alpha^{\prime}}{0.4}}+\left(\bar{\lambda}_{0}-\sqrt{\frac{\alpha^{\prime}}{0.4}}\right)\left(1-\frac{1}{(a / b)^{0.1}}\right)=\sqrt{\frac{0.575}{0.4}}+\left(0.288-\sqrt{\frac{0.575}{0.4}}\right)\left(1-\frac{1}{(2)^{0.1}}\right)=1.138 .
$$

The elastic critical local buckling stress is:

$$
f_{\text {cr }}=\frac{E}{\sqrt{3\left(1-v^{2}\right)}} \frac{2 t}{D_{\text {eq }}}=\frac{210000}{\sqrt{3\left(1-0.3^{2}\right)}} \frac{2 \times 4.0}{600}=1694 \mathrm{MPa} .
$$

The nondimensionalised local buckling slenderness is:

$$
\bar{\lambda}_{\ell}=\sqrt{\frac{f_{\mathrm{y}}}{f_{\mathrm{cr}}}}=\sqrt{\frac{450}{1694}}=0.515
$$

Since $\bar{\lambda}_{0}<\bar{\lambda}_{\ell}<\bar{\lambda}_{\mathrm{p}}, \rho=\rho_{1}=1-\mu \frac{\bar{\lambda}_{\ell}-\bar{\lambda}_{0}}{\bar{\lambda}_{\mathrm{p}}-\bar{\lambda}_{0}}$ where: 


$$
\begin{aligned}
& \beta_{1}=1-\frac{1}{(a / b)^{0.5}}=1-\frac{1}{(2)^{0.5}}=0.293 \\
& \beta_{2}=\frac{0.09+\alpha^{\prime}}{(a / b)}-0.09=\frac{0.09+0.575}{2}-0.09=0.243 \\
& \mu=1-\frac{\beta_{1}}{\bar{\lambda}_{\mathrm{p}}}-\frac{\beta_{2}}{\bar{\lambda}_{\mathrm{p}}{ }^{2}}=1-\frac{0.293}{1.138}-\frac{0.257}{1.138^{2}}=0.544
\end{aligned}
$$

Therefore the strength reduction factor is:

$$
\rho=1-\mu \frac{\bar{\lambda}_{\ell}-\bar{\lambda}_{0}}{\bar{\lambda}_{\mathrm{p}}-\bar{\lambda}_{0}}=1-(0.544)\left(\frac{0.515-0.288}{1.138-0.288}\right)=0.855
$$

The design compressive resistance of the cross-section is given by:

$$
N_{\mathrm{c}, \mathrm{Rd}}=A_{\text {eff }} f_{\mathrm{y}}=\rho A f_{\mathrm{y}}=0.855 \times 2857 \times 450=1099 \mathrm{kN}
$$

\section{Example 2}

In the second example, the design resistance of one of the experimental specimens used in the validation study is to be determined. Specimen number 3 is a $500 \times 250 \times 8$ EHS member, with a modulus of elasticity $E=216400 \mathrm{MPa}$ and a yield strength $f_{y}=413 \mathrm{MPa}$ [4].

The cross-sectional slenderness of the section is 219 , so the section is indeed Class 4 .

The imperfection amplitude $\Delta w=1.58 \mathrm{~mm}$.

The imperfection factor $\alpha^{\prime}=0.580$.

The local buckling limit slenderness $\bar{\lambda}_{0}=0.288$.

The plastic limit slenderness $\bar{\lambda}_{\mathrm{p}}=1.143$.

The elastic critical local buckling stress $f_{\text {cr }}=2096 \mathrm{MPa}$

The nondimensionalised local buckling slenderness $\bar{\lambda}_{\ell}=0.444$

Since $\bar{\lambda}_{0}<\bar{\lambda}_{\ell}<\bar{\lambda}_{\mathrm{p}}, \rho=\rho_{1}=1-\mu \frac{\bar{\lambda}_{\ell}-\bar{\lambda}_{0}}{\bar{\lambda}_{\mathrm{p}}-\bar{\lambda}_{0}}$ where: 
$\beta_{1}=0.293$

$\beta_{2}=0.245$

$\mu=0.556$

The strength reduction factor $\rho=0.899$

The design compressive resistance of the cross-section is given by:

$N_{\mathrm{c}, \mathrm{Rd}}=\rho A f_{\mathrm{y}}=0.899 \times 9492 \times 413=3523 \mathrm{kN}$

The experimental ultimate load for this specimen is $3615 \mathrm{kN} \mathrm{[4],} \mathrm{therefore} \mathrm{the} \mathrm{ratio} \mathrm{of} \mathrm{the}$ experimental result to the predicted design resistance is $3615 / 3523=1.026$, signifying that the design prediction is both safe and accurate. Similar analyses of Specimens 1 and 2 used in the validation study returned ratios of 1.064 and 1.004 , respectively. 
Figure 1 Cross-sectional geometry of an EHS

Figure 2 Examples of elastic buckling mode shapes for EHS tubes with different aspect ratios Figure 3 Comparison of numerical and experimental deformation modes

Figure 4 Validation of numerical model against test results for load-end shortening behaviour Figure 5 Summary of failure modes observed in parametric study models

Figure 6 Normalised load-end shortening responses of EHS stub columns with $a / b=1.1$

Figure 7 Normalised load-end shortening responses of EHS stub columns with $a / b=1.5$

Figure 8 Normalised load-end shortening responses of EHS stub columns with $a / b=2.0$

Figure 9 Normalised load-end shortening responses of EHS stub columns with $a / b=3.0$

Figure 10 Normalised load-end shortening responses of EHS stub columns with $a / b=5.0$

Figure 11 Strength reduction factors for sections with $a / b=1.1$

Figure 12 Strength reduction factors for sections with $a / b=1.5$

Figure 13 Strength reduction factors for sections with $a / b=2.0$

Figure 14 Strength reduction factors for sections with $a / b=3.0$

Figure 15 Strength reduction factors for sections with $a / b=5.0$

Figure 16 Plot of ratios of ultimate load from the main parametric study $f_{\mathrm{u}, 1}$ to ultimate loads calculated using alternative imperfection mode shape $f_{\mathrm{u}, 2}$ against slenderness

Figure 17 Summary of proposed design strength reduction curves for Class 4 EHS members in compression (Class A imperfections)

Figure 18 Comparison of ratios of numerical ultimate load to design ultimate load for proposed EHS design method and equivalent diameter CHS design method for $a / b=1.1$ (Class A imperfections)

Figure 19 Comparison of ratios of numerical ultimate load to design ultimate load for proposed EHS design method and equivalent diameter CHS design method for $a / b=1.5$ (Class A imperfections)

Figure 20 Comparison of ratios of numerical ultimate load to design ultimate load for proposed EHS design method and equivalent diameter CHS design method for $a / b=2.0$ (Class A imperfections)

Figure 21 Comparison of ratios of numerical ultimate load to design ultimate load for proposed EHS design method and equivalent diameter CHS design method for $a / b=3.0$ (Class A imperfections)

Figure 22 Comparison of ratios of numerical ultimate load to design ultimate load for proposed EHS design method and equivalent diameter CHS design method for $a / b=5.0$ (Class A imperfections) 


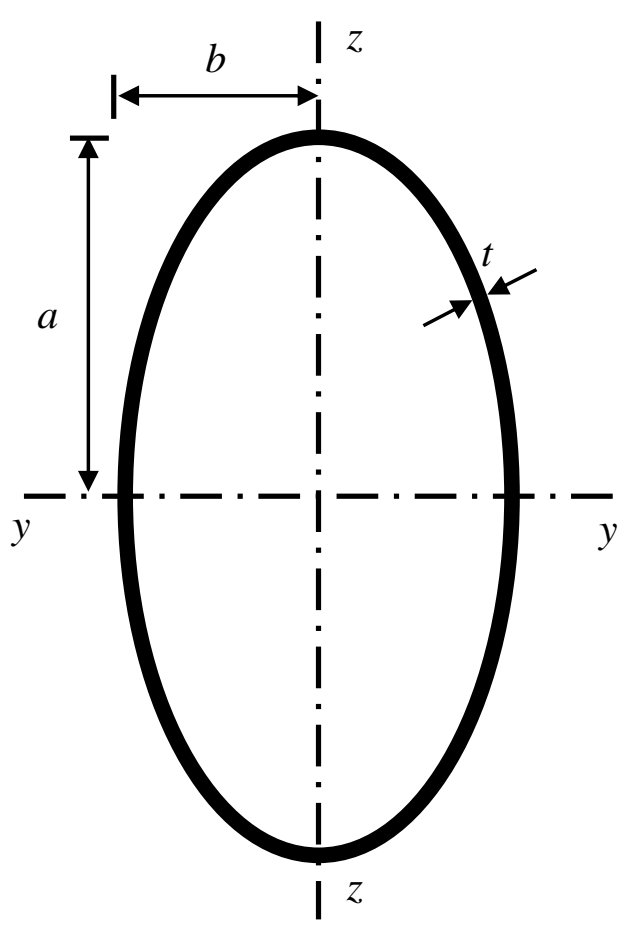

Figure 1

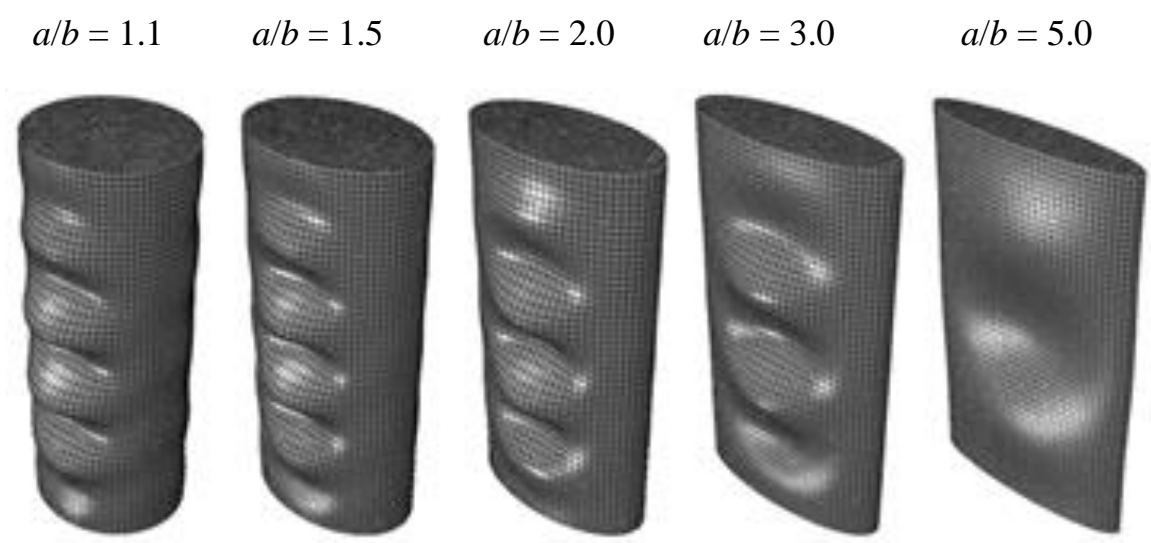

Figure 2 


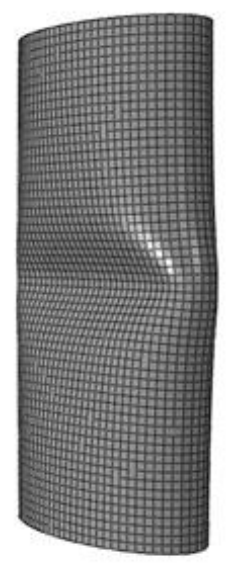

Numerical prediction

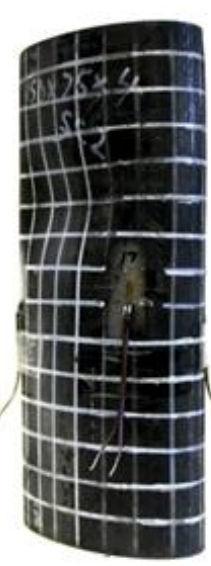

Experimental result

Figure 3
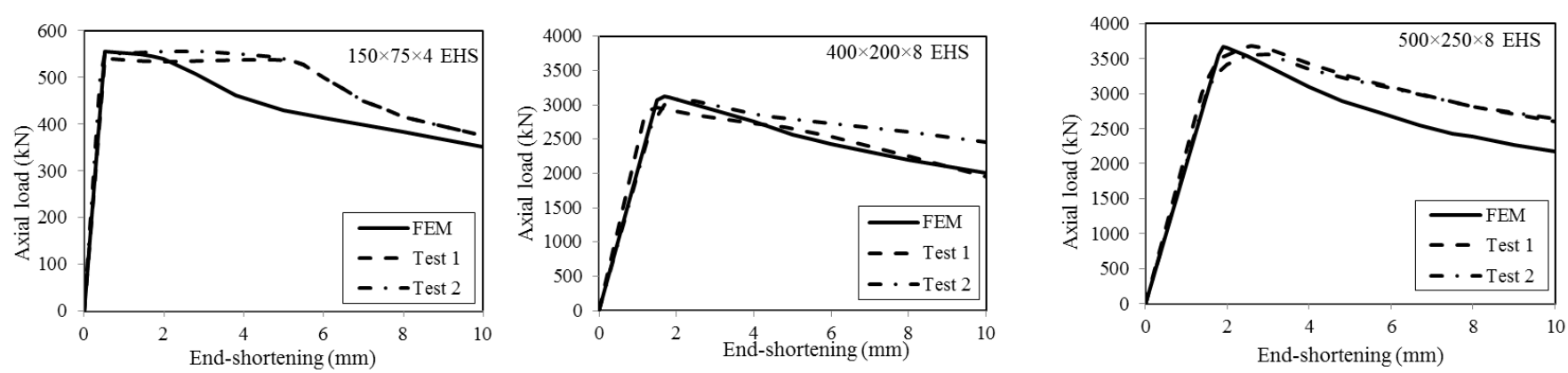

Figure 4 

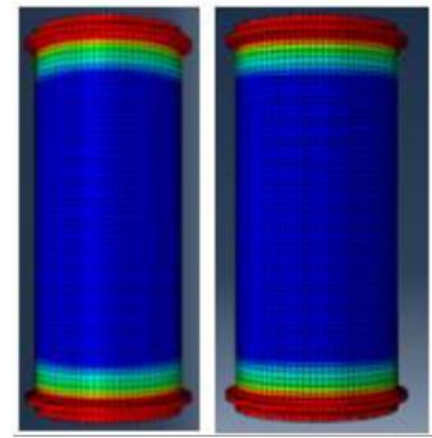

$a / b=1.1, f_{\mathrm{y}}=390.6 \mathrm{MPa}$

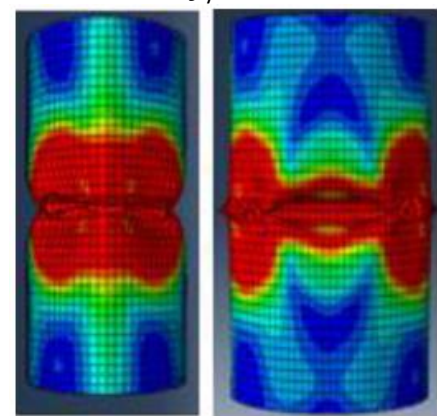

$a / b=1.5, f_{\mathrm{y}}=390.6 \mathrm{MPa}$
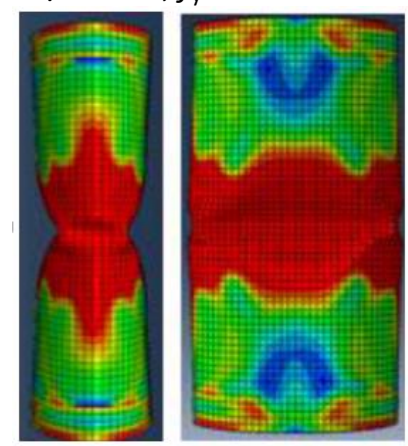

$a / b=2.0, f_{\mathrm{y}}=390.6 \mathrm{MPa}$

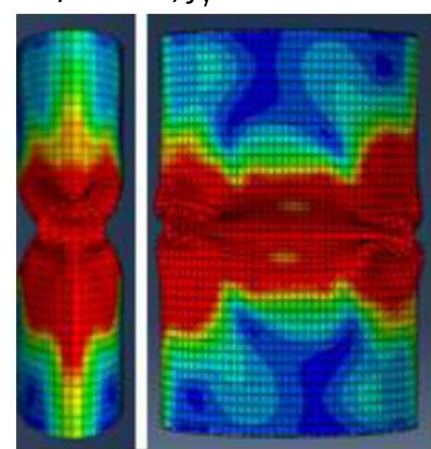

$a / b=3.0, f_{\mathrm{y}}=390.6 \mathrm{MPa}$

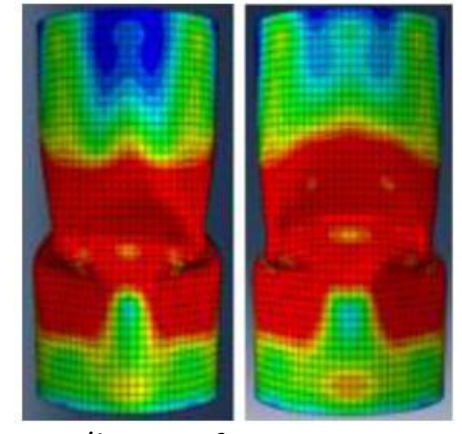

$a / b=1.1, f_{\mathrm{y}}=1500 \mathrm{MPa}$

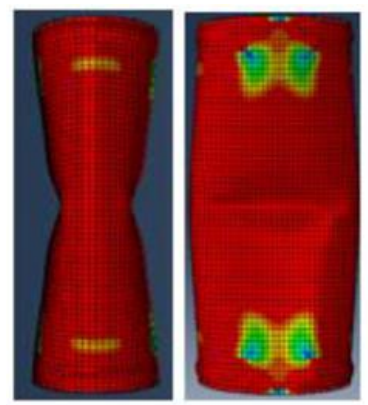

$a / b=1.5, f_{\mathrm{y}}=1200 \mathrm{MPa}$

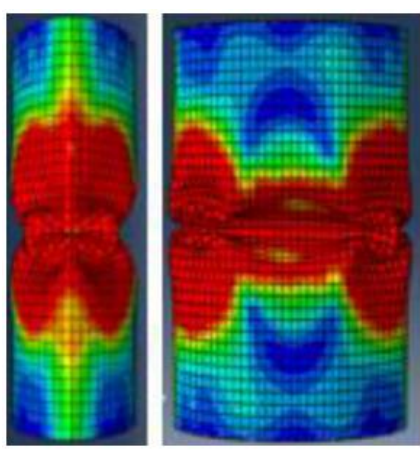

$a / b=2.0, f_{\mathrm{y}}=900 \mathrm{MPa}$

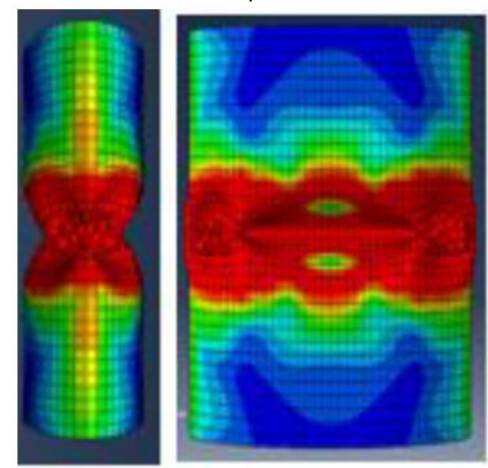

$a / b=3.0, f_{\mathrm{y}}=700 \mathrm{MPa}$ 


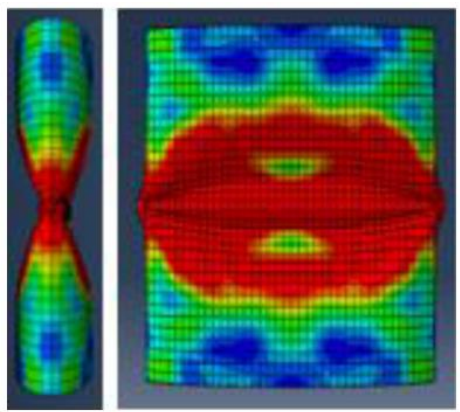

$a / b=5.0, f_{\mathrm{y}}=390.6 \mathrm{MPa}$

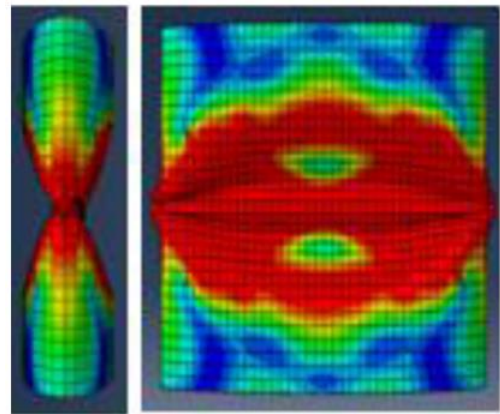

$a / b=5.0, f_{\mathrm{y}}=500 \mathrm{MPa}$

Figure 5
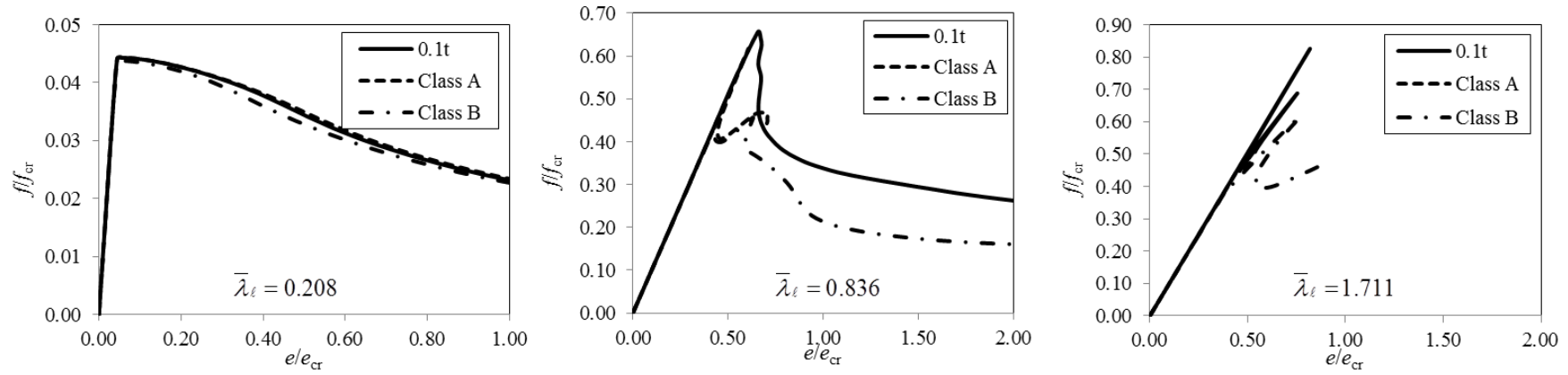

Figure 6
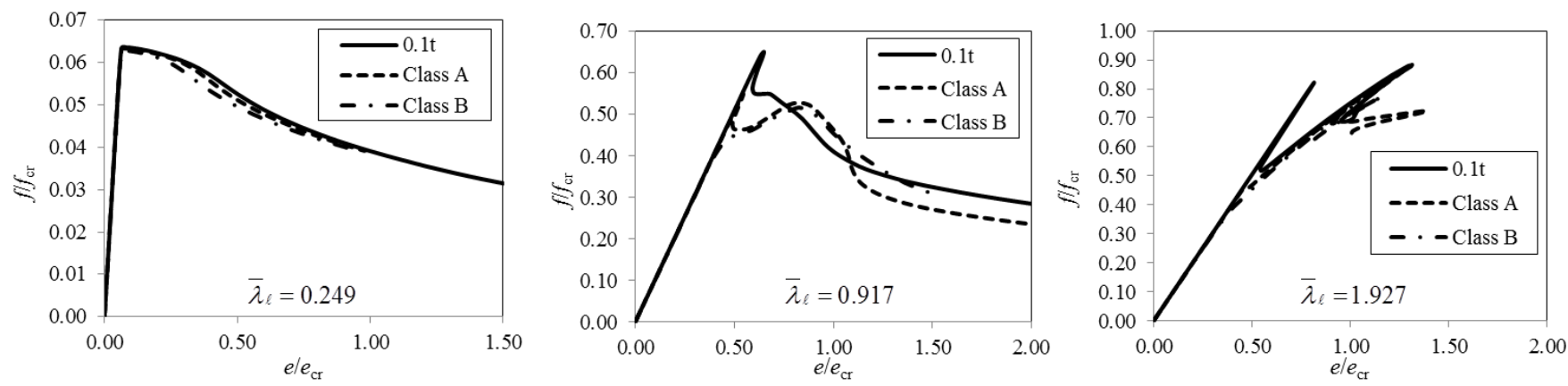

Figure 7
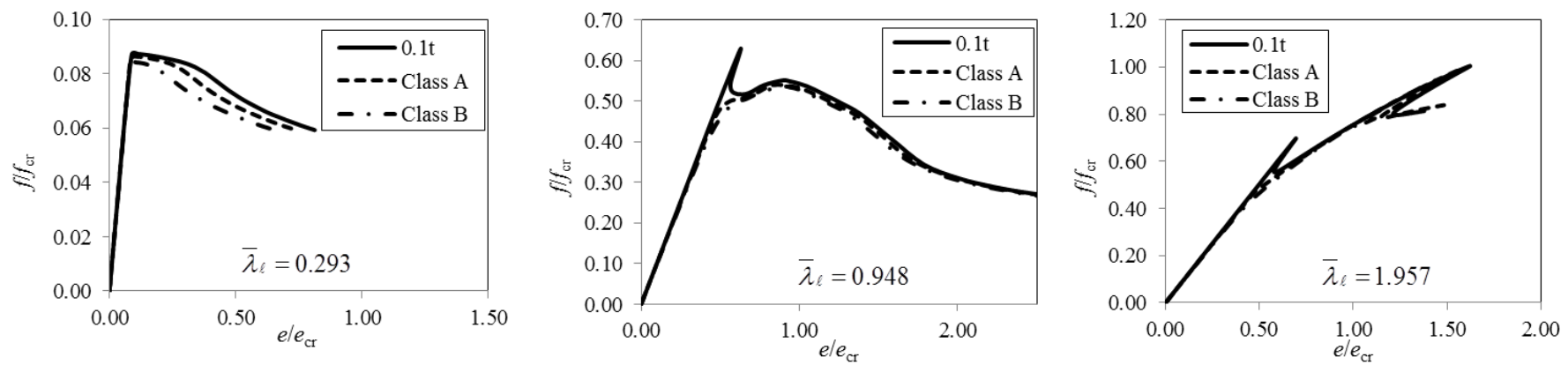

Figure 8 

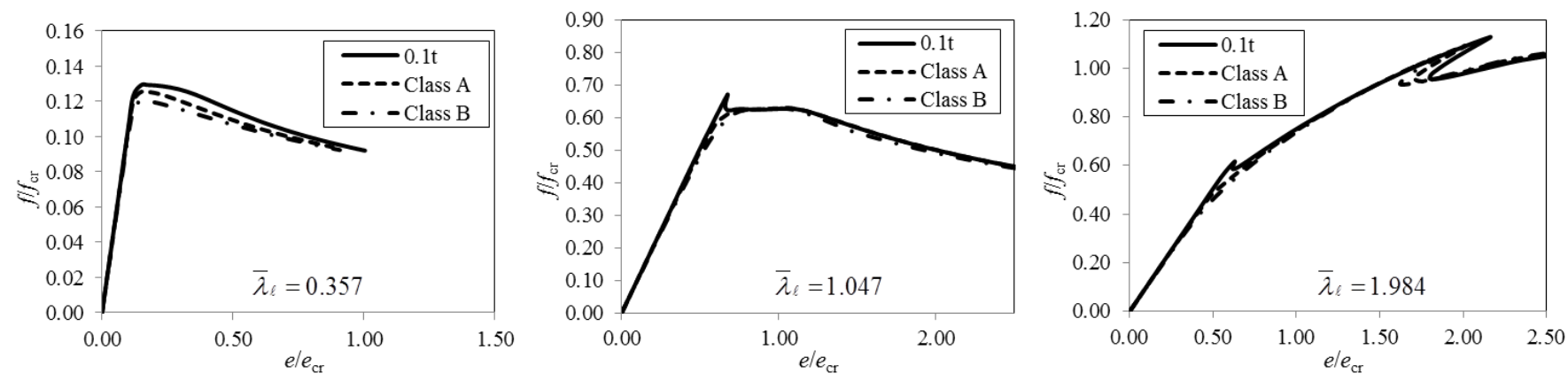

Figure 9
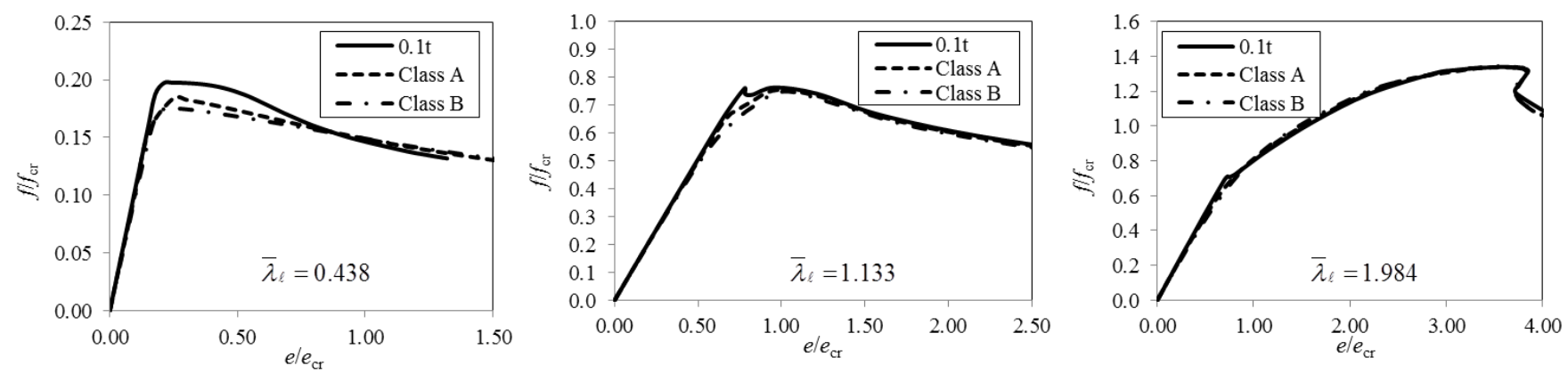

Figure 10

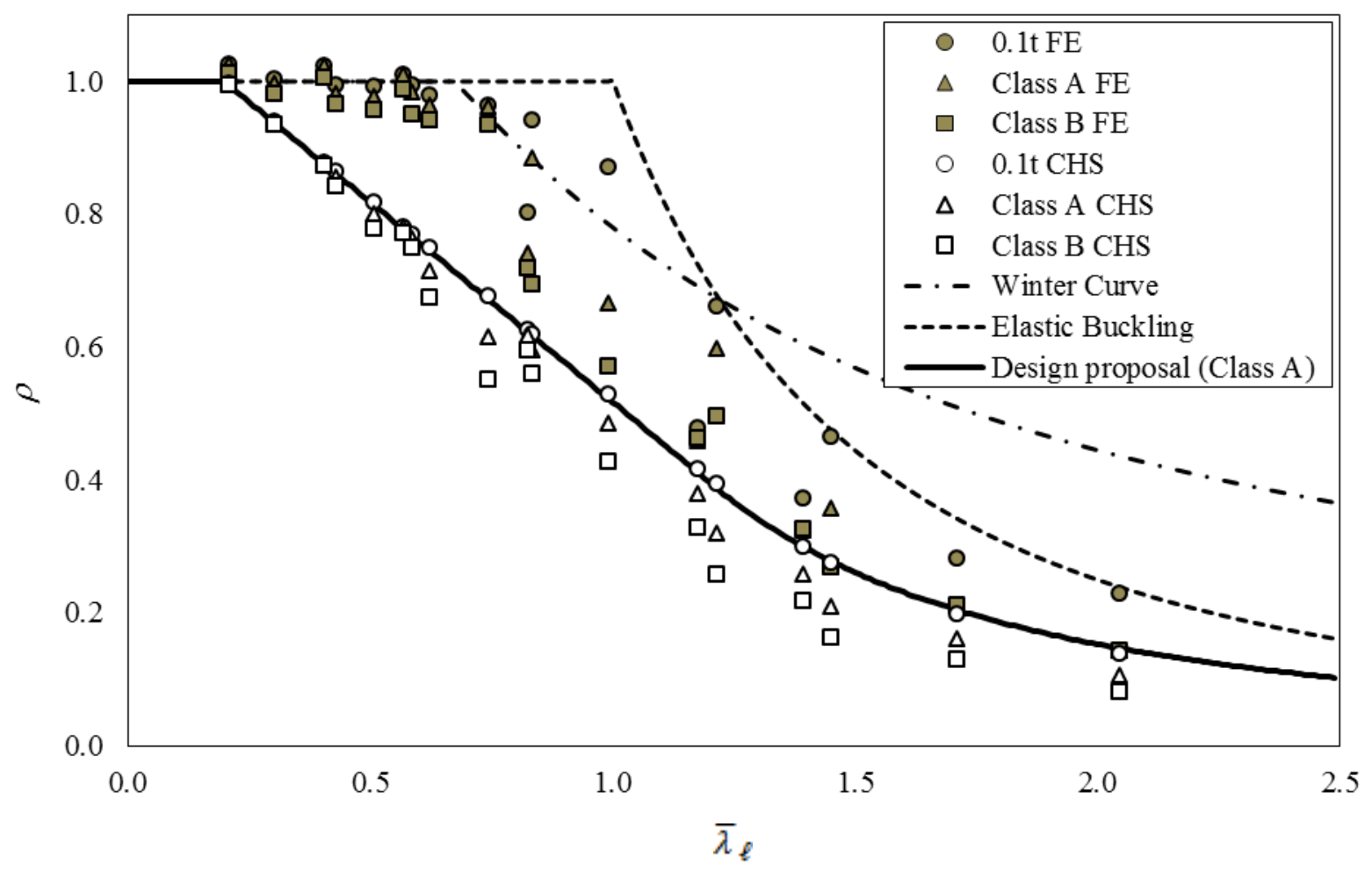

Figure 11 


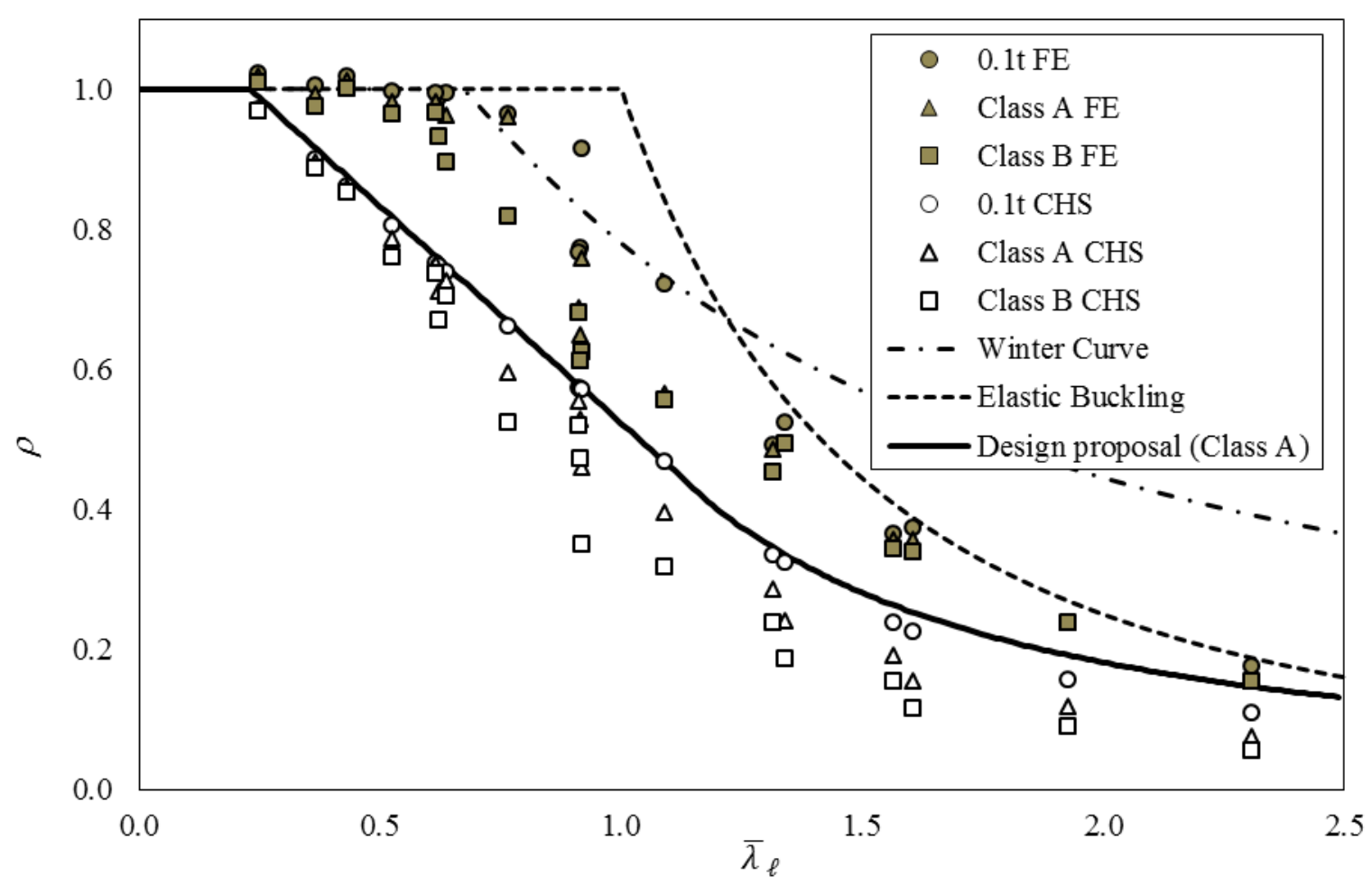

Figure 12

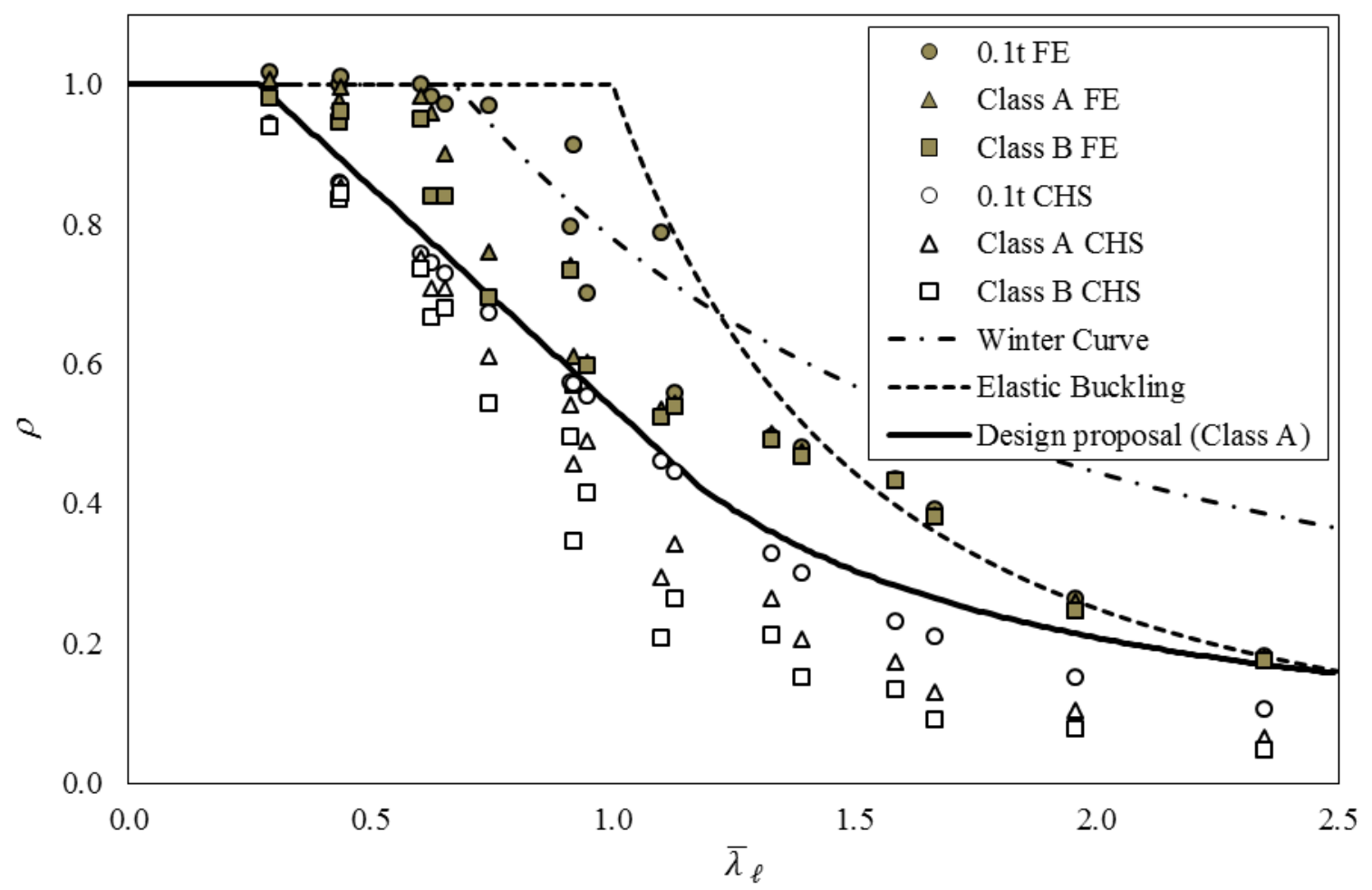

Figure 13 


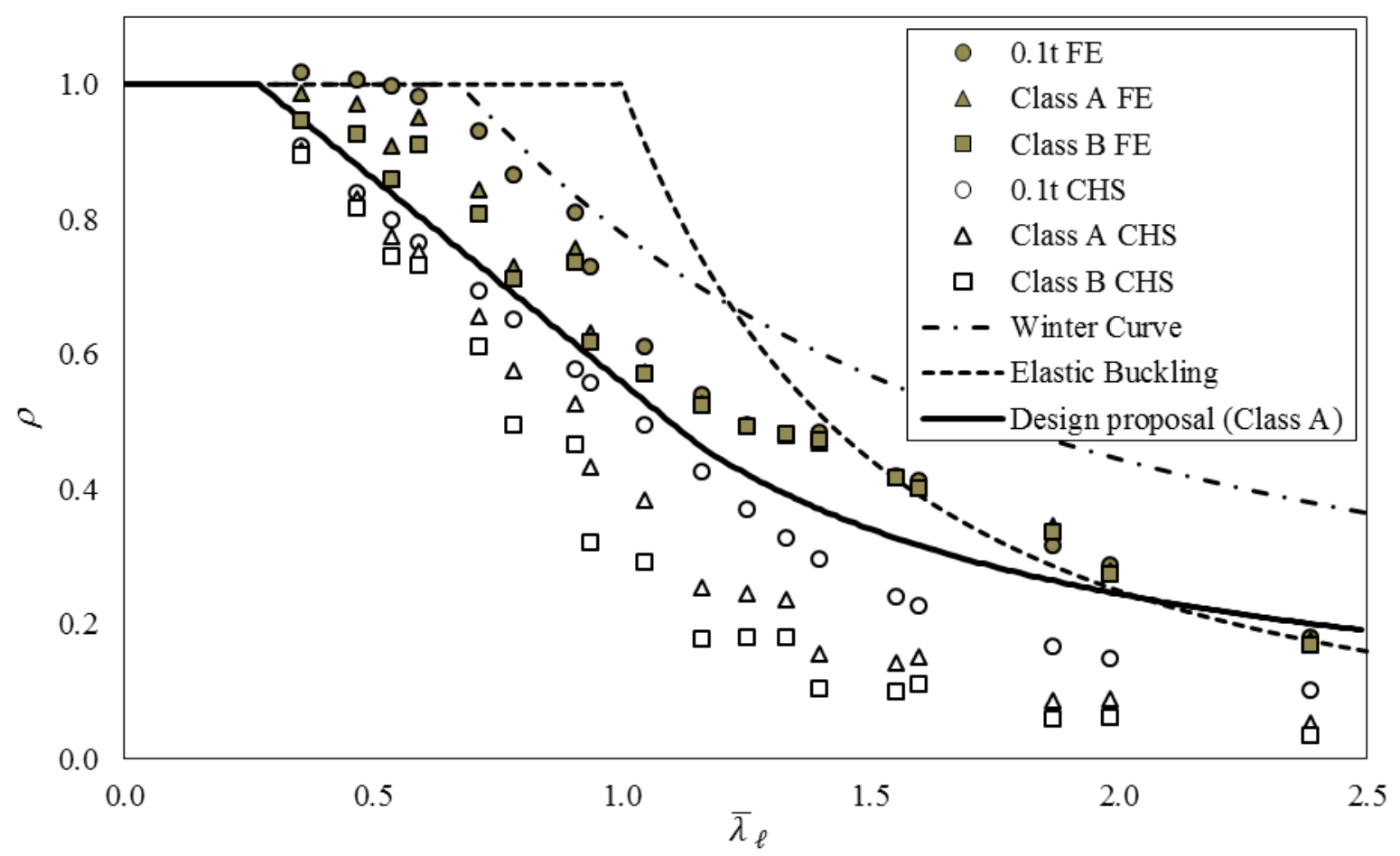

Figure 14

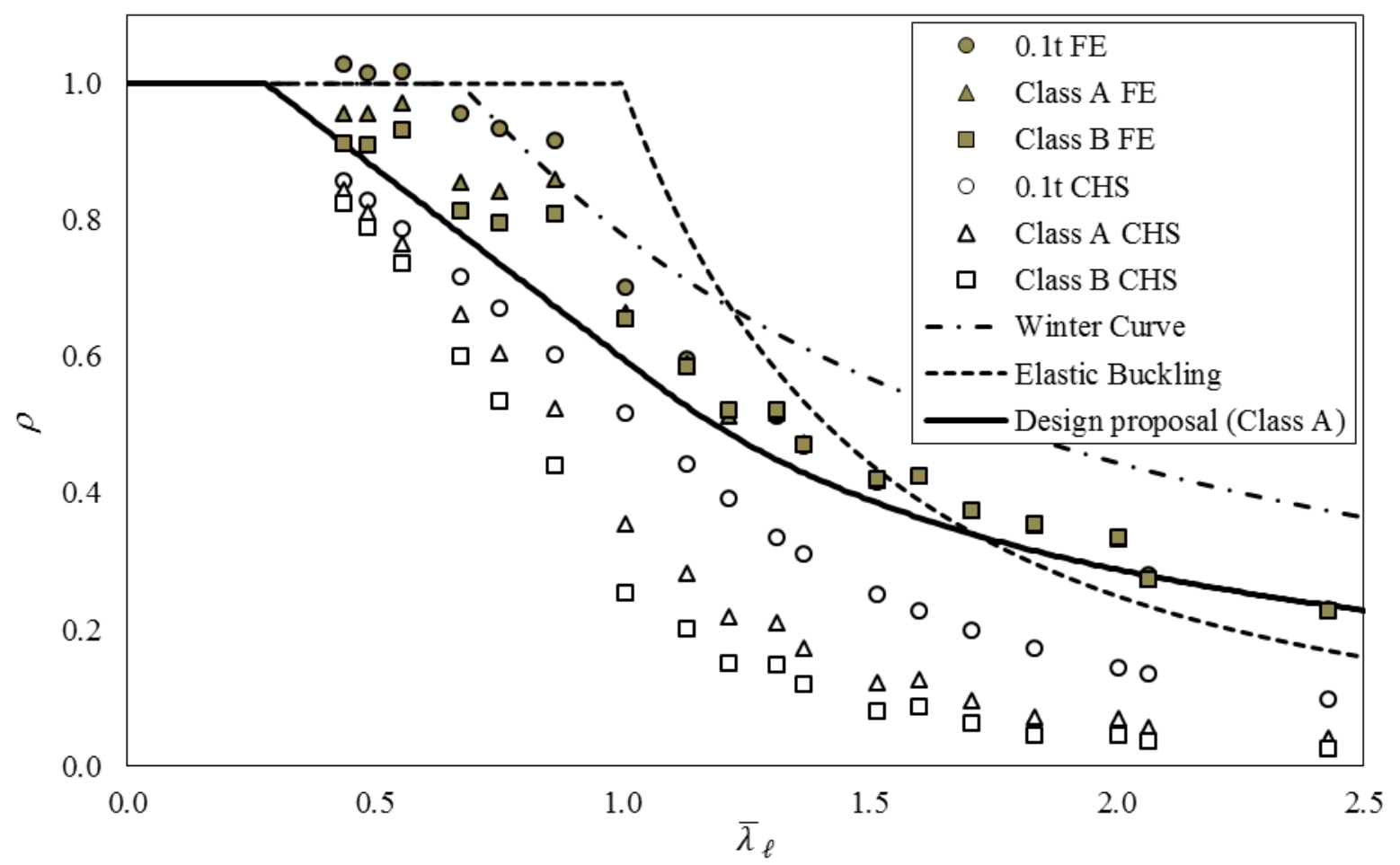

Figure 15 


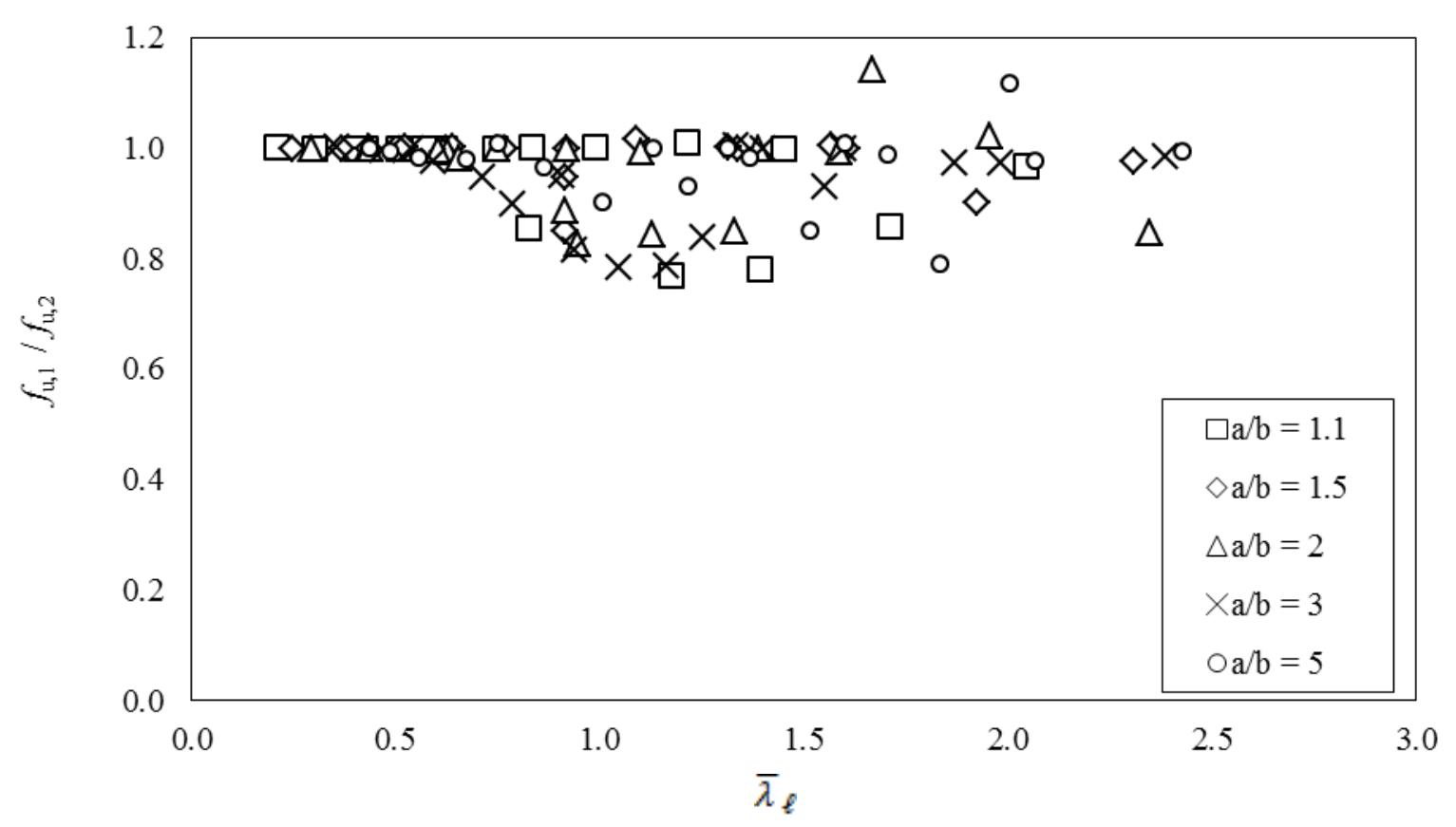

Figure 16

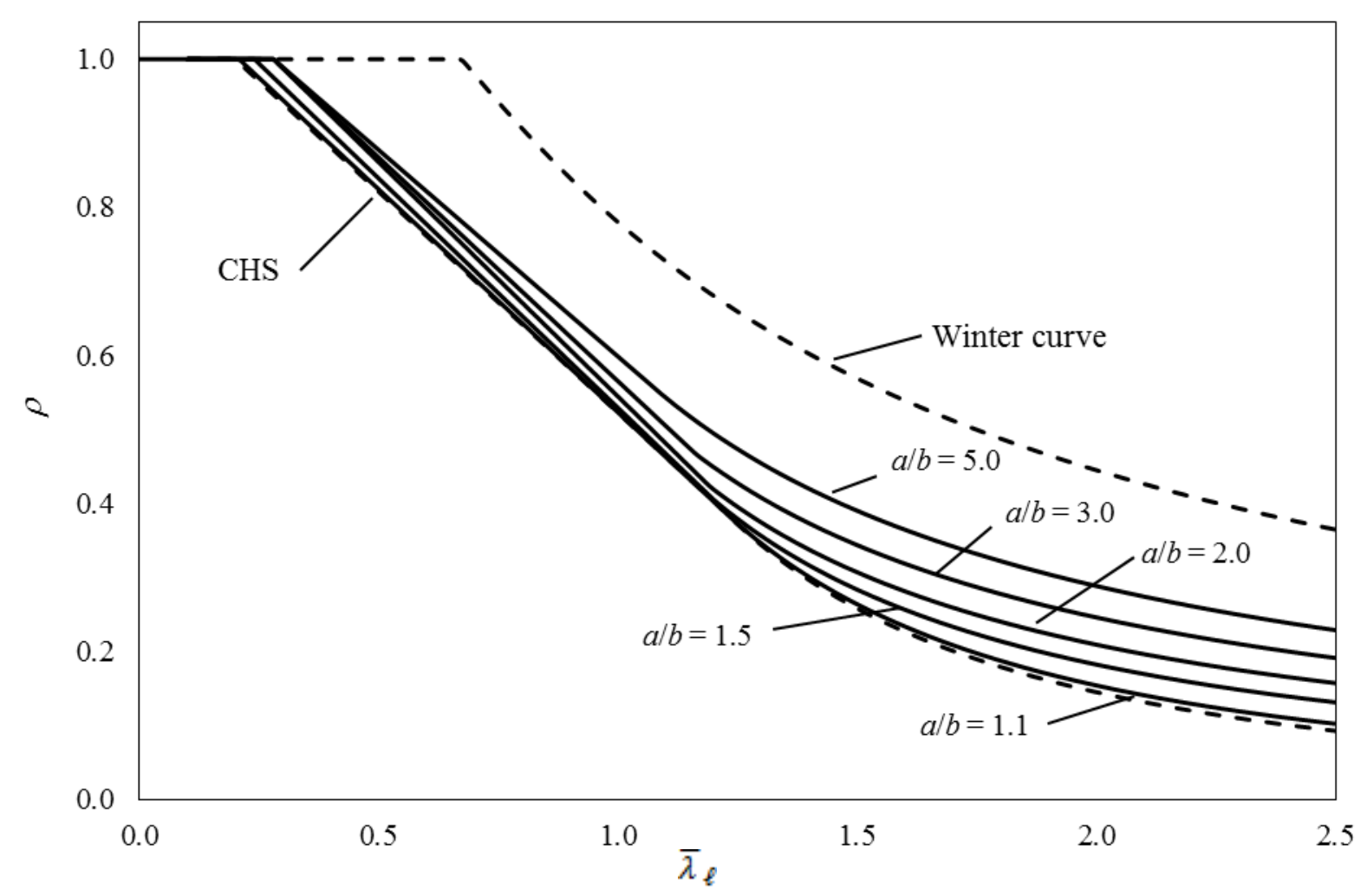

Figure 17 


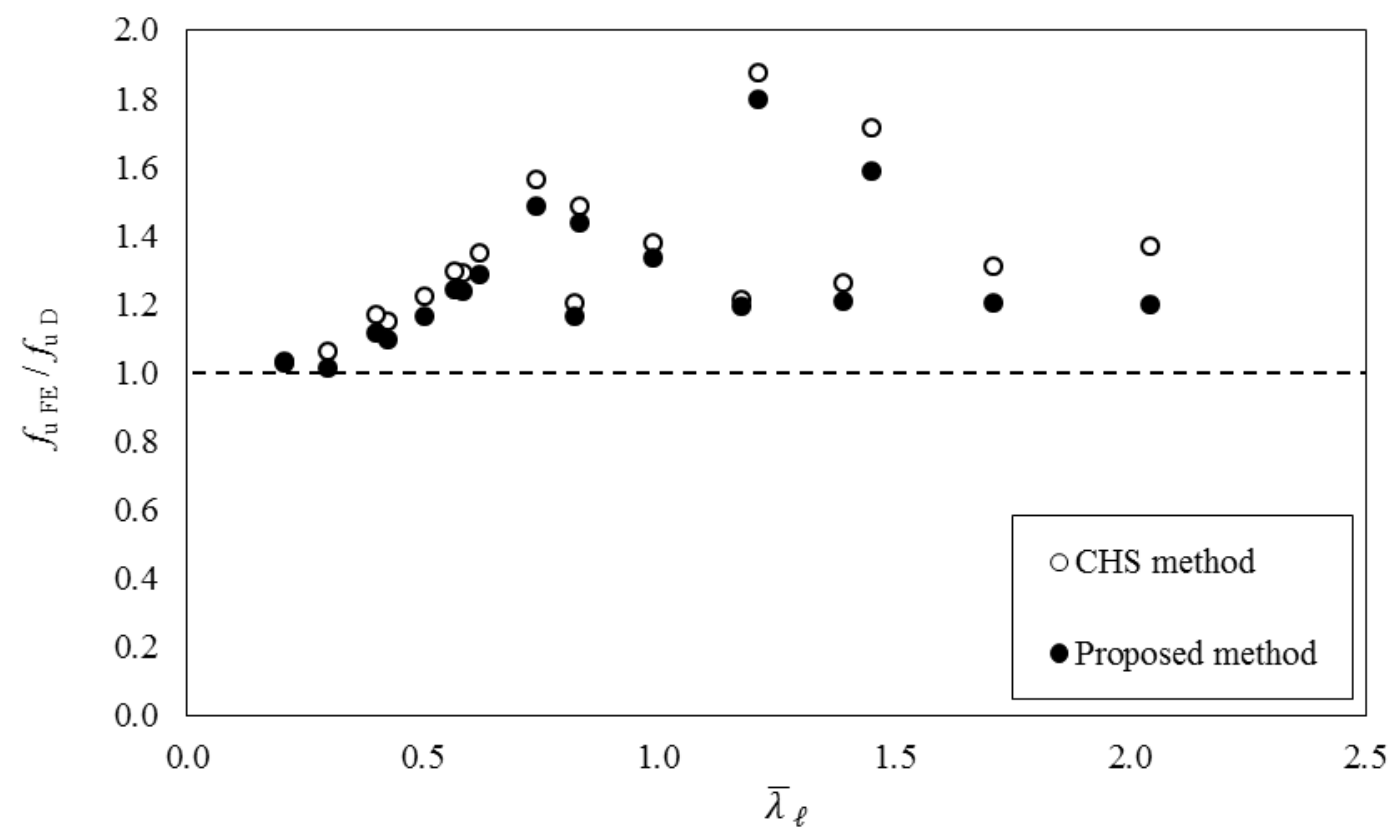

Figure 18

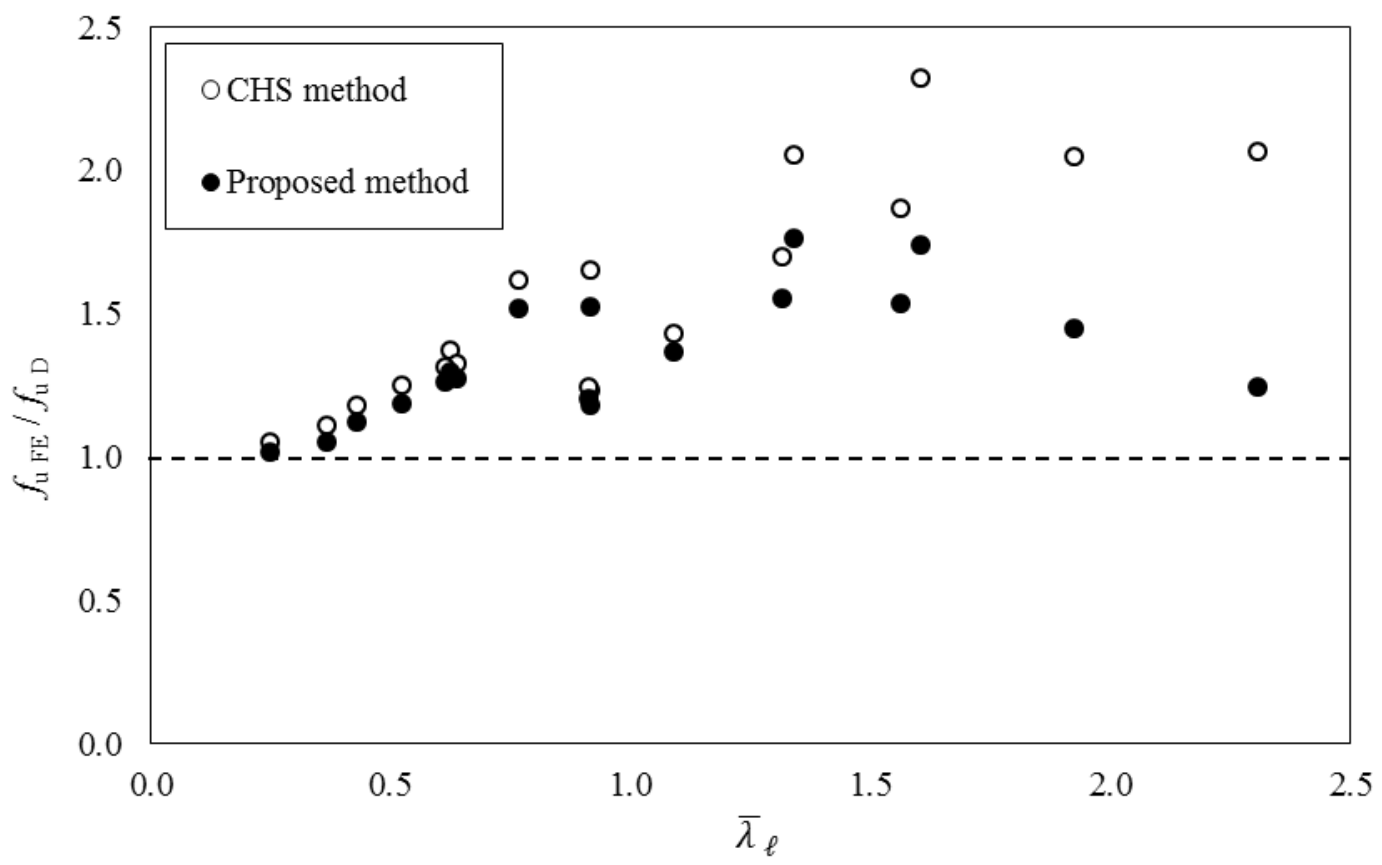

Figure 19 


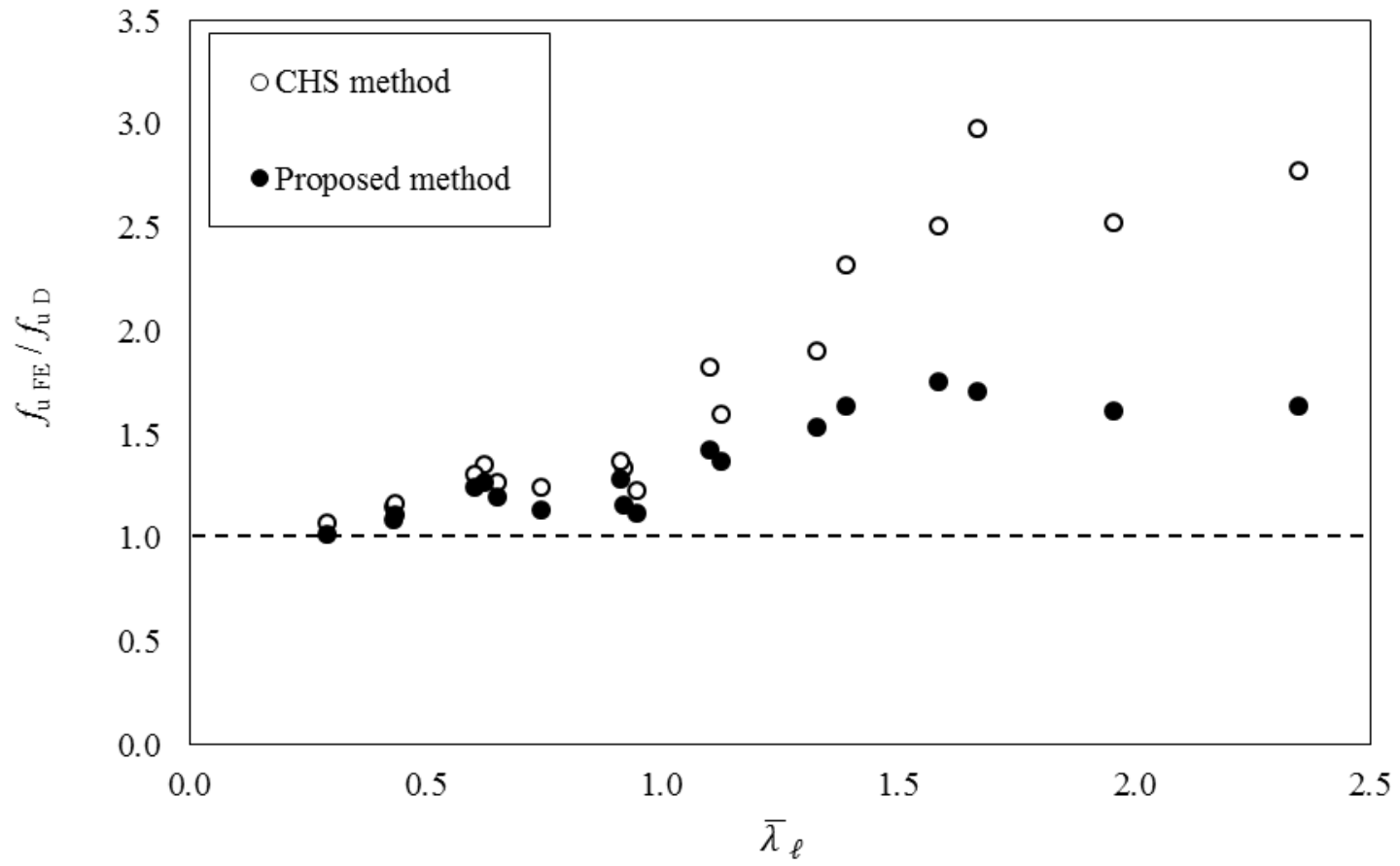

Figure 20

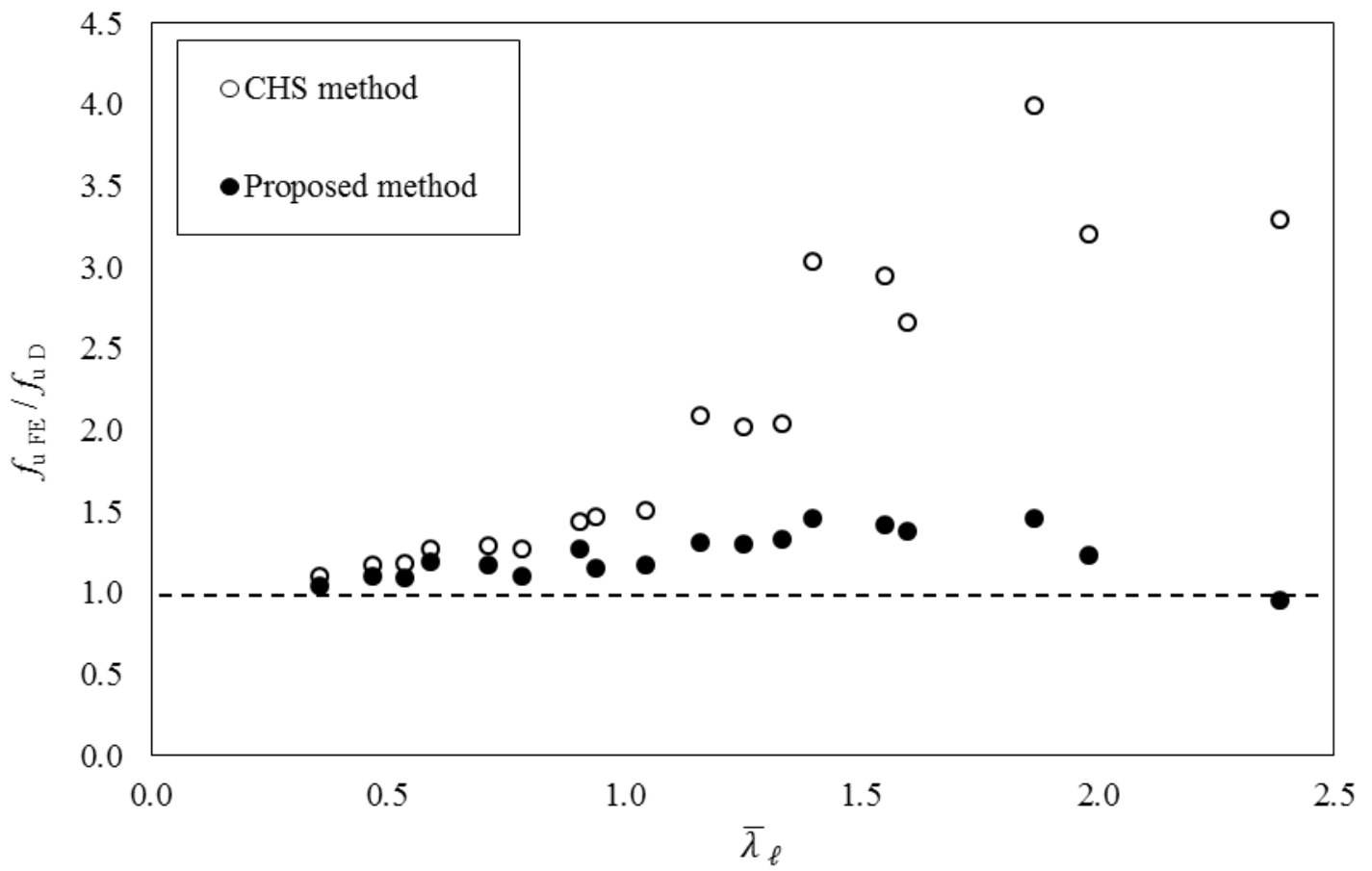

Figure 21 


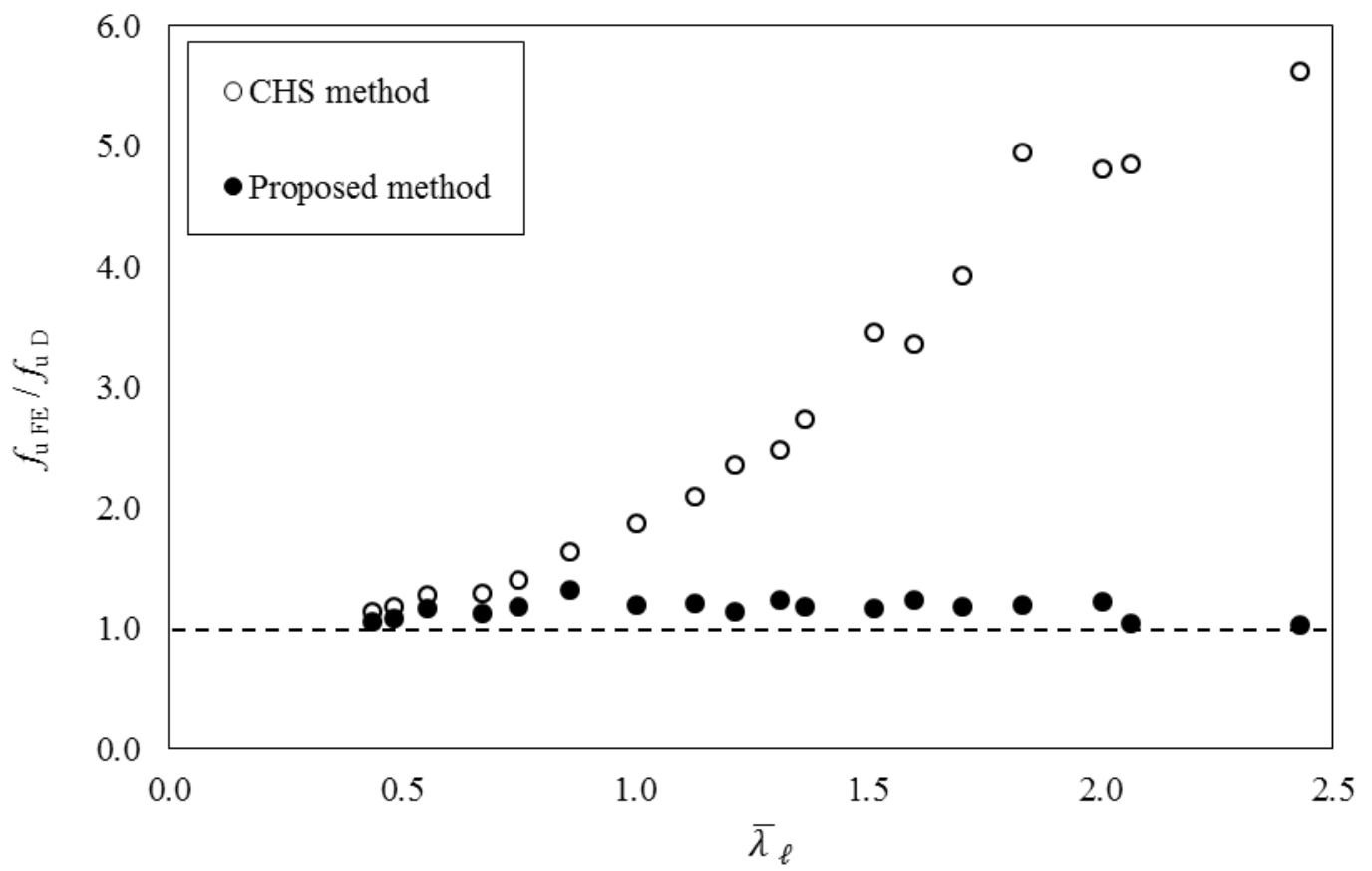

Figure 22 
Table 1

\begin{tabular}{c|cc|cc|cc}
\hline$a / b$ & $\begin{array}{c}f_{\mathrm{y}} \\
(\mathrm{MPa})\end{array}$ & $\begin{array}{c}t_{\mathrm{imp}} \\
(\mathrm{mm})\end{array}$ & $\begin{array}{c}f_{\mathrm{y}} \\
(\mathrm{MPa})\end{array}$ & $\begin{array}{c}t_{\text {imp }} \\
(\mathrm{mm})\end{array}$ & $\begin{array}{c}f_{\mathrm{y}} \\
(\mathrm{MPa})\end{array}$ & $\begin{array}{c}t_{\text {imp }} \\
(\mathrm{mm})\end{array}$ \\
\hline 1.1 & 390.6 & 8.7 & 1500 & 8.7 & 3000 & 4.2 \\
1.5 & 390.6 & 8.7 & 1200 & 8.7 & 2500 & 4.2 \\
2.0 & 390.6 & 8.7 & 900 & 4.2 & 1800 & 2.1 \\
3.0 & 390.6 & 2.1 & 700 & 2.1 & 1150 & 2.1 \\
5.0 & 390.6 & 1.0 & 500 & 1.0 & 700 & 0.7 \\
\hline
\end{tabular}

Table 2

\begin{tabular}{cccc}
\hline Section & $\begin{array}{c}\text { Test ultimate load } \\
(\mathrm{kN})\end{array}$ & $\begin{array}{c}\text { Predicted FE ultimate } \\
\text { load }(\mathrm{kN})\end{array}$ & Error $(\%)$ \\
\hline $150 \times 75 \times 4$ EHS & 546 & 553 & 1.3 \\
$400 \times 200 \times 8$ EHS & 3021 & 3138 & 3.9 \\
$500 \times 250 \times 8$ EHS & 3615 & 3662 & 1.3 \\
\hline
\end{tabular}

Table 3

\begin{tabular}{|c|c|c|c|c|c|c|c|c|}
\hline \multirow{2}{*}{ Section series } & \multirow{2}{*}{$\begin{array}{c}t \\
(\mathrm{~mm})\end{array}$} & \multirow{2}{*}{$\begin{array}{c}f_{y} \\
(\mathrm{MPa})\end{array}$} & \multirow{2}{*}{$\begin{array}{c}f_{c r} \\
(\mathrm{MPa})\end{array}$} & \multirow{2}{*}{$\bar{\lambda}_{\ell}$} & \multirow{2}{*}{$\begin{array}{c}L \\
(\mathrm{~mm})\end{array}$} & \multicolumn{3}{|c|}{$\Delta w(\mathrm{~mm})$} \\
\hline & & & & & & $0.1 t$ & Class A & Class B \\
\hline \multirow{18}{*}{$\begin{array}{c}242 \times 220 \\
(a / b=1.1)\end{array}$} & 8.7 & \multirow{6}{*}{390.6} & 8695 & 0.21 & 600 & 0.87 & 0.85 & 1.36 \\
\hline & 4.2 & & 4227 & 0.30 & 600 & 0.42 & 0.59 & 0.95 \\
\hline & 2.1 & & 2115 & 0.43 & 600 & 0.21 & 0.42 & 0.67 \\
\hline & 1.5 & & 1511 & 0.51 & 600 & 0.15 & 0.35 & 0.57 \\
\hline & 1.0 & & 1007 & 0.62 & 600 & 0.10 & 0.29 & 0.46 \\
\hline & 0.7 & & 705 & 0.74 & 600 & 0.07 & 0.24 & 0.39 \\
\hline & 8.7 & \multirow{6}{*}{1500} & 8695 & 0.42 & 400 & 0.87 & 0.85 & 1.36 \\
\hline & 4.2 & & 4227 & 0.60 & 400 & 0.42 & 0.59 & 0.95 \\
\hline & 2.1 & & 2115 & 0.84 & 400 & 0.21 & 0.42 & 0.67 \\
\hline & 1.5 & & 1511 & 1.00 & 400 & 0.15 & 0.35 & 0.57 \\
\hline & 1.0 & & 1007 & 1.22 & 400 & 0.10 & 0.29 & 0.46 \\
\hline & 0.7 & & 705 & 1.46 & 400 & 0.07 & 0.24 & 0.39 \\
\hline & 8.7 & \multirow{6}{*}{3000} & 8695 & 0.59 & 300 & 0.87 & 0.85 & 1.36 \\
\hline & 4.2 & & 4227 & 0.84 & 300 & 0.42 & 0.59 & 0.95 \\
\hline & 2.1 & & 2115 & 1.19 & 300 & 0.21 & 0.42 & 0.67 \\
\hline & 1.5 & & 1511 & 1.41 & 300 & 0.15 & 0.35 & 0.57 \\
\hline & 1.0 & & 1007 & 1.73 & 300 & 0.10 & 0.29 & 0.46 \\
\hline & 0.7 & & 705 & 2.06 & 300 & 0.07 & 0.24 & 0.39 \\
\hline \multirow{11}{*}{$\begin{array}{c}274.8 \times 183.2 \\
(a / b=1.5)\end{array}$} & 8.7 & \multirow{6}{*}{390.6} & 6057 & 0.25 & 600 & 0.87 & 1.06 & 1.69 \\
\hline & 4.2 & & 2856 & 0.37 & 600 & 0.42 & 0.74 & 1.18 \\
\hline & 2.1 & & 1404 & 0.53 & 600 & 0.21 & 0.52 & 0.83 \\
\hline & 1.5 & & 998 & 0.63 & 600 & 0.15 & 0.44 & 0.70 \\
\hline & 1.0 & & 661 & 0.77 & 600 & 0.10 & 0.36 & 0.57 \\
\hline & 0.7 & & 462 & 0.92 & 600 & 0.07 & 0.30 & 0.48 \\
\hline & 8.7 & \multirow{5}{*}{1200} & 6057 & 0.45 & 400 & 0.87 & 1.06 & 1.69 \\
\hline & 4.2 & & 2856 & 0.65 & 400 & 0.42 & 0.74 & 1.18 \\
\hline & 2.1 & & 1404 & 0.92 & 400 & 0.21 & 0.52 & 0.83 \\
\hline & 1.5 & & 998 & 1.10 & 400 & 0.15 & 0.44 & 0.70 \\
\hline & 1.0 & & 661 & 1.35 & 400 & 0.10 & 0.36 & 0.57 \\
\hline
\end{tabular}




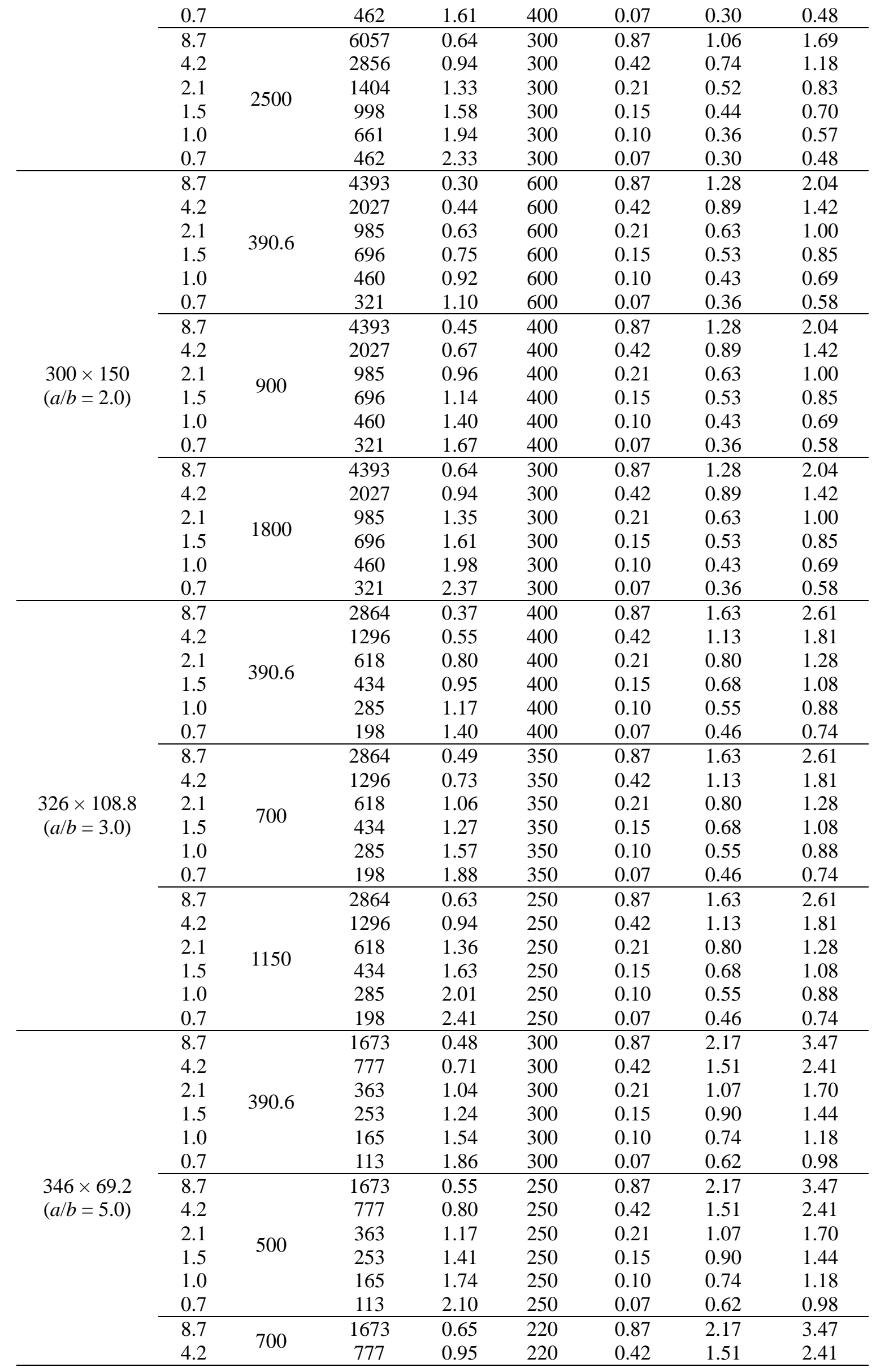




\begin{tabular}{lllllll}
\hline 2.1 & 363 & 1.39 & 220 & 0.21 & 1.07 & 1.70 \\
1.5 & 253 & 1.66 & 220 & 0.15 & 0.90 & 1.44 \\
1.0 & 165 & 2.06 & 220 & 0.10 & 0.74 & 1.18 \\
0.7 & 113 & 2.49 & 220 & 0.07 & 0.62 & 0.98 \\
\hline
\end{tabular}

